\title{
Precipitation Extremes Influence Patterns and Partitioning of Evapotranspiration and Transpiration in a Deciduous Boreal Larch Forest
}

\section{Citation}

Liu, JiaLin, FangYan Cheng, J. William Munger, Peng Jiang, Timothy G. Whitby, SiYue Chen, WeiWen Ji, XiuLing Man. 2020. Precipitation Extremes Influence Patterns and Partitioning of Evapotranspiration and Transpiration in a Deciduous Boreal Larch Forest. Agricultural and Forest Meteorology 287: 107936.

\section{Permanent link}

http://nrs.harvard.edu/urn-3:HUL.InstRepos:42643006

\section{Terms of Use}

This article was downloaded from Harvard University's DASH repository, and is made available under the terms and conditions applicable to Open Access Policy Articles, as set forth at http:// nrs.harvard.edu/urn-3:HUL.InstRepos:dash.current.terms-of-use\#OAP

\section{Share Your Story}

The Harvard community has made this article openly available.

Please share how this access benefits you. Submit a story.

\section{Accessibility}




\section{Precipitation extremes influence patterns and partitioning of evapotranspiration}

and transpiration in a deciduous boreal larch forest

1, 2JiaLin Liu, 3FangYan Cheng, *2, 4J. William Munger, 2, 5 Peng Jiang, 2 Timothy G.

Whitby, 4, 6SiYue Chen, 4, 6 WeiWen Ji, *7XiuLing Man

1Arts and Science, New York University Shanghai, 1555 Century Avenue, Shanghai, 200122, China;

2School of Engineering and Applied Sciences, Harvard University, 29 Oxford Street, Cambridge, 02138, USA;

3School of Life Sciences, Fudan University, 2005 Songhu Road, Shanghai, 200438, China;

4Department of Earth and Planetary Sciences, Harvard University, 20 Oxford Street, Cambridge, 02138, USA;

5College of Urban and Environmental Sciences, Peking University, 5 Yiheyuan Road, Beijing, 100871, China;

6School of Physics, Peking University, 5 Yiheyuan Road, Beijing, 100871, China;

7School of Forestry, Northeastern Forestry University, Harbin, 26 Hexing Road, 150040, China.

\section{*Corresponding authors:}

J. William Munger (jwmunger@seas.harvard.edu)

XiuLing Man (mannefu@163.com)

\section{Acknowledgment:}

1) Authors declare no conflict of interests.

2) The work is funded by the National Natural Science Foundation of China (No. 31770488). This study is supported by the Harvard China Project, a component of the Harvard Global Institute at Harvard University.

3) Ecosystem water fluxes, sap-flow fluxes, and micro-meteorological observations adopted in this study are available on the Harvard Dataverse at https://doi.org/10.7910/DVN/MQYWBQ.

4) GPCP Precipitation data provided by the NOAA/OAR/ESRL PSD, Boulder, Colorado, USA, at https://www.esrl.noaa.gov/psd/.

5) Wang X.M., Sheng H.C., Duan B.X., Hu Y., Song H., from Northeast Forestry University contributed to collection of field data. We thank Liu H.L., affiliated with SITP-CAS and Boston University, for review of fundamental physical equations, codes, and machine learning algorithms used in this study. 


\section{Abstract}

High latitude boreal forests are experiencing dramatic changes in climate and hydrology. It is not clear how boreal forests will adapt to hydrological change or how stable they will be to extreme climate fluctuations and shifts in ecosystem water availability (EWA; residuals between precipitation and evapotranspiration). Although there have been numerous studies in North American and European boreal forests, the Siberian boreal region is underrepresented. Moreover, Siberia is dominated by deciduous conifers (larch) that may have different response to shifting hydrology than boreal evergreens do. We observed evapotranspiration (ET) by eddy covariance technique and transpiration $(T)$ by sap-flow probes on a subsample of trees within the flux-tower footprint through two growing seasons in a larch forest in northernmost China. Ecosystems at the margins of their zone could be amongst the first to experience significant shifts in structure and function. At this site there have already been signs of permafrost degradation and more frequent temperature and precipitation anomalies. The canopy-dominant larch accounted for half the total $T$ fluxes. The remaining 50\% was distributed evenly among intermediate and suppressed trees. $T$ is the dominant subcomponent in $E T$, where overall $T / E T$ varies of $66 \%-84 \%$ depending on precipitation patterns. In dormant and early growing seasons, $T$ still constitutes a majority of $E T$ even though the canopy foliage is not fully developed because cold soil creates a negative soil to air vapor pressure gradient that impedes evaporation. However, in the peak growing season, excess precipitation reduces $T$ while providing sufficient wetness for surface evaporation. ET from standard data product based on MODIS satellite reflectance underestimates tower ET by $17 \%-29 \%$. Solar-induced chlorophyll fluorescence measured by satellite is well correlated with tower ET ( $r_{2}=$ 0.69-0.73) and could provide a better basis for regional ET extrapolations. A global comparison of data for 2000-2018 period reveals that boreal forests not only have the smallest annual MODIS ET but also the least EWA compared to temperate and tropical forests. Also, even though boreal deciduous and evergreens have comparable annual ET, their $T / E T$ and EWA are distinct. This work highlights how short-term precipitation extremes may shift ecosystem function and structure by changing EWA through exported runoff. Sites along boreal ecotones are critical to observe for signs of shifts in their structure, function, and response to climate anomalies.

Keywords Ecosystem stability; Precipitation extreme; Climate anomaly; Phenology; Boreal forests 


\section{Introduction}

\section{Overview on the significance of studying boreal water exchanges}

Evapotranspiration $(E T)$ is a significant component in global hydrological cycling and land-atmosphere energy balances (Good et al., 2015). ET includes the exchange of water from the land surface to the atmosphere by the abiotic evaporation and biotic transpiration (Katul et al., 2012). ET is critical but challenging to accurately predict because it links two different pathways of water vaporization and also interacts with the climate closely (Shukla et al., 1990). Forest ecosystems are the essential engine in the terrestrial water exchanges (Jasechko et al., 2013; Schlaepfer et al., 2014; Schlesinger and Jasechko, 2014). Thus, they are of great interest to foresters, ecologists, hydrologists, and climatologists for understanding ET and transpiration across a range of spatial scales and various ecosystem types (Kool et al., 2014). Quantifying the ratio of transpiration to ET (T/ET) contributes to understanding ecosystem carbon-water coupling and cycling (Austin et al., 2004). Accurate representation of ET partitioning and its influence on land-atmosphere patterns is essential for realistic climate simulations (Lawrence et al., 2007).

Increasing studies have explored the $T / E T$ across many terrestrial ecosystems by field experiments (Yepez et al., 2003; Moran et al., 2009; Scanlon and Kustas, 2010; Cavanaugh et al., 2011; Tian et al., 2011; Raz-Yaseef et al., 2012; Sun et al., 2014; Kool et al., 2016), meta-analysis (Jasechko et al., 2013; Coenders-Gerrits et al., 2014; Schlesinger and Jasechko, 2014; Wang et al., 2014; Wei et al., 2017), and ensemble modeling (Lawrence et al., 2007). Based on a global synthesis (Schlesinger and Jasechko, 2014), transpiration accounts for $61 \%$ of terrestrial ET. Boreal forests, temperate forests and tropical rainforests make distinct contributions (reanalyzed in Figure S1).

\section{Climate change influences the stability of boreal ecosystems}

Over the past 30 years climate change in northern ecosystems, has led to a decline of ground albedo following more frequent wildfires and permafrost degradation (Tchebakova et al., 2009). The release of previously frozen carbon by permafrost thawing may amplify climate change (Melillo et al., 2002; Schuur et al., 2015). On annual to decadal time scales, climate change strongly alters precipitation and temperature patterns (Lotsch et al., 2003). Regional temperature-precipitation complexity influences vegetation phenology (Goulden et al., 1996; White et al., 1999; Nolan et al., 2018), in particular, boreal forest's mortality and hydraulic vulnerability are very sensitive to climate extremes (Peng et al., 2011; Way et al., 2013). The Siberian ecoregion is one of the largest boreal forest in the world (Watson et al., 2018), which serves as a significant carbon sink. Hence, amplified climate change, degraded permafrost, and the increased chance of temperature-precipitation anomalies are challenging the resilience and stability of boreal forests in Siberia (Tchebakova et al., 2009). Warmer temperatures have contributed to expanding boreal forest into tundra at the northern tree-line (Esper and Schweingruber, 2011), and simultaneously to the expansion of temperate forest into boreal forest at the southern margin (Evans and Brown, 2017). 
Northeast China, which is at the southern margin of the Siberian zone, contains 3.8 $\times 105 \mathrm{~km} 2$ of permafrost that is experiencing severe degradation (Jin et al., 2007). The degradation is occurring in the discontinuous permafrost zone as well as continuous permafrost zones. Permafrost degradation influences ecosystem energy and mass exchange that will impact overlying vegetation (Yi et al., 2014). Much of this region is covered by vulnerable larch forests intermingled with early succession birch/aspen stands and scattered Mongolian Scots pines.

\section{Water flux measurements and remotely-sensed indicators}

Many direct and indirect measurement approaches have been developed for estimating ET and its sub-components since the 1970s (Kool et al., 2014), including micro-lysimeters (Deguchi et al., 2008), sap-flow measurements (Granier et al., 1985), isotopic tracing (Jasechko et al., 2013), eddy covariance (Wilson et al., 2001), hydrological process-based modeling (Estevez et al., 2009), energy balance residual (Amiro, 2009), and carbon-water correlation (Scanlon et al., 2010). Direct measurements by the eddy covariance method are considered to be the most reliable and accurate approach so far (Tian et al., 2011). Indirect methods usually depend on several theoretical assumptions that add additional uncertainties (Shi et al., 2008).

Algorithms based on remote-sensing data provide estimates of ET on regional to global scales (Velpuri et al., 2013). For instance, the Moderate Resolution Imaging Spectroradiometer (MODIS) ET is a mature data product with good spatial resolution and extended temporal coverage and has been used for global synthesis already (Schlesinger and Jasechko, 2014). However, it has not been extensively evaluated against field observations in the widespread, critical Siberian ecosystem (Mu et al., 2011). Observations are needed to test whether empirical ecosystem parameters based on evergreen conifers can be applied to the boreal deciduous conifers in Siberia (Reich et al., 1998).

Meanwhile, solar-induced chlorophyll fluorescence (SIF) is an emerging technique that observes vegetation's photosynthetic processes by quantifying the fluorescent radiation emission (Joiner et al., 2014). Increasing studies show SIF has potentials to track ecosystem water and carbon dynamics from the single site to the globe (Lee et al., 2013; Guan et al., 2015; Sun et al., 2015; Lu et al., 2018). However, there are no studies available to determine whether SIF is a reliable indicator for ET estimations in boreal larch forest.

\section{Uncertainties on boreal water budget evaluations}

Currently, there are two knowledge gaps in global ET and transpiration evaluations. First, uncertain ET budgets in boreal larch ecozones. Larch is the deciduous conifer that dominates Siberian boreal forests with a total area of $6.8 \times 106 \mathrm{~km} 2$ (Abaimov, 2010; Pan et al., 2011). Ecosystem functional traits of deciduous larch are distinct from evergreen conifers (Reich et al., 1998). However, global ecohydrological studies have not included larch at all, which has left uncertainties in evaluating regional to global water budgets (Jasechko et al., 2013; Schlesinger and Jasechko, 2014).

Second, daily transpiration fluxes estimated from sap-flow measurements remain uncertain because the relative contributions of xylem refilling and actual water losses to nocturnal sap flow (Fisher et al., 2007) have not been adequately determined for 
many plant functional types, in particular, boreal larch forest.

Furthermore, the response of boreal larch's hydrology to microclimate driving forces (e.g., temperature, humidity, radiation, etc.) is still unclear. In general, forest ET and transpiration are controlled strictly by atmospheric vapor pressure deficit and solar radiation (Motzer et al., 2005; Mackay et al., 2007). Temperature is an essential regulator for some ecosystem types (Law et al., 2002), though its tight correlation with radiation, especially at high latitudes, makes it difficult to separate these influences. Shifting of inter-annual precipitation patterns will also introduce uncertainties into correlations between forest hydrology and climatic drivers (Trenberth, 2011; Endo et al., 2017).

In this study, we focus on the overarching objective of understanding how ET in boreal larch forest responds to precipitation changes. Secondly, we seek to distinguish xylem refilling from actual water loss so that nighttime sap-flow observations can be accurately accounted. Additionally, we examine key methodological issues that affect the ability to estimate water budgets over larger spatial scales and longer intervals. How well can ET for boreal larch forest be estimated from remote-sensing data such as MODIS reflectances or satellite derived SIF? How well can machine learning algorithms estimate $E T$ and enable prediction at places and times where measurements fail?

\section{Methodology}

\subsection{Site description}

The Mohe (Moh) ecological research station $\left(53^{\circ} 27^{\prime} 59^{\prime \prime} \mathrm{N}, 122^{\circ} 20^{\prime} 06^{\prime \prime} \mathrm{E}\right)$ is located in the Mohe County, Northeast China (location in the globe and IGBP types were highlighted in Figure 1a). The study area is within the zone of Eurasian continuous permafrost. The site near the Mohe tower is fairly flat with the elevation of $290 \mathrm{~m}$ a.s.1 in the Amur River valley (Figure 1b), and it also lies at the northern part of the Greater Hinggan Mountains and near the southern edge of Siberia with similar flora and climate. Regional mean annual temperature (1959-2017) is $-5.5^{\circ} \mathrm{C}$ and the mean annual precipitation in the same period is $460.8 \mathrm{~mm}$ with approximately $70 \%$ occurring as rainfall during warmer months (i.e., June to September). Also, Shannon Diversity Indices of the satellite pixel in Figure 1c showed the site is uniform (Richness $=2.0$, Evenness $=0.24$ ).

The native forest is dominated by Dahurian larch (Larix gmelinii), along with the evergreen Scots pine (Pinus sylvestris var. mongolica), and two deciduous broadleaf trees, white birch (Betula platyphylla) and aspen (Populus davidiana). Understory vegetation includes ledum (Ledum palustre), lingonberry (Vaccinium vitis-Idaea), saussurea (Saussurea japonica), Dahurian rhododendron (Rhododendron dauricum), and blueberry (Vaccinium uliginosum). Tree heights of larch were $12.4 \pm 4.2 \mathrm{~m}$ (mean \pm s.d.) with $11.1 \pm 5.9 \mathrm{~cm}$ diameter at breast height and $7.1 \pm 5.2 \mathrm{~m} 2$ canopy area in 2015 (Table S1). Understory heights were $0.1-2.0 \mathrm{~m}$ with $3 \%-76 \%$ ground coverages. Land use/land cover change in Mohe was insignificant from 1990-2010 (Figure S2). In 2010, larch forest covered 56\% lands in Mohe county $(1.0 \times 104$ of $1.8 \times 104 \mathrm{~km} 2)$ with negligible change (expansion by $\sim 100 \mathrm{~km} 2$ ) since 1990. 


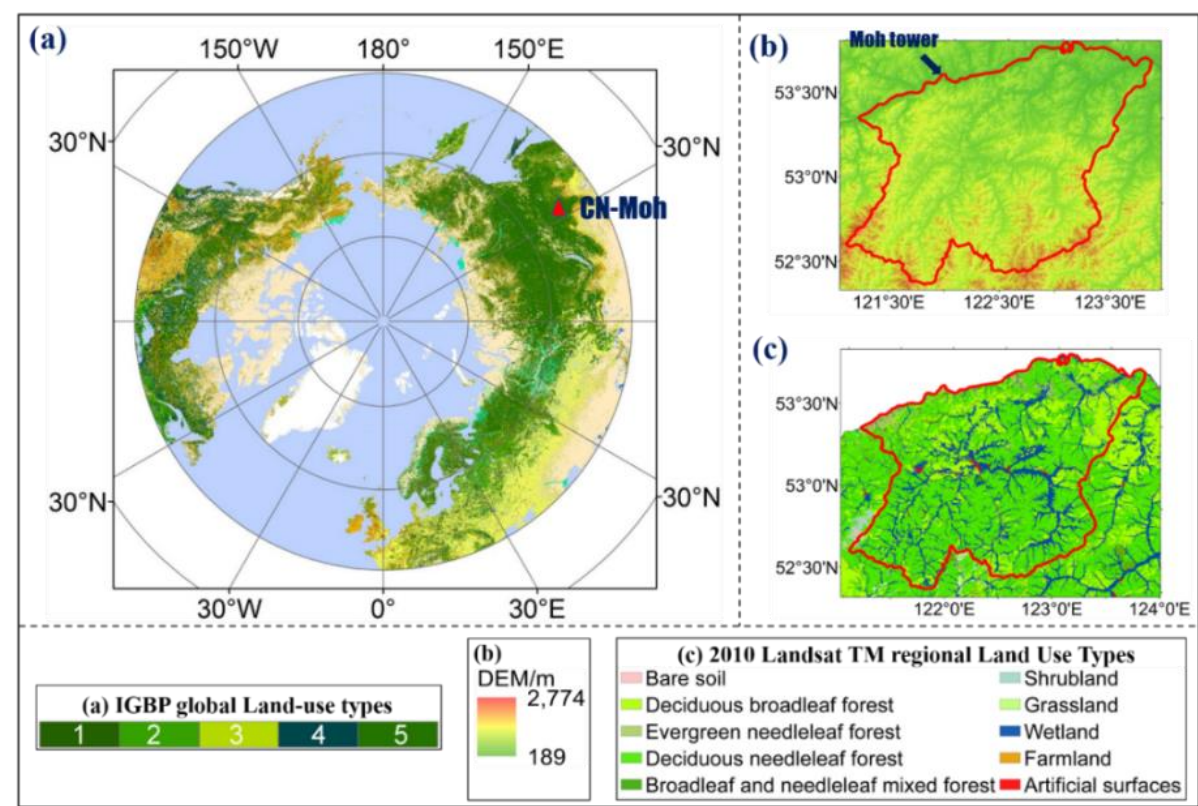

Figure 1. Panels (a): Landcover map for the boreal-arctic region north of $45^{\circ}$ (Globcover2009: http://due.esrin.esa.int/page_globcover.php). Panel (b): DigitalElevation-Model (DEM) of Mohe. Panel (c): Regional land use map in Mohe county based on Landsat TM images in 2010. The red polygon is the border of Mohe county. The 30-m spatial resolution DEM data was downloaded from the Geospatial Data Cloud (http://www.gscloud.cn/). The 30-m spatial resolution land use map was selfinterpreted from the Landsat $5 \mathrm{TM}$ images (https://landsat.usgs.gov/) and plotted on the base map. IGBP legend in (a): (1) Closed to open (ground cover $>15 \%$ ) broadleaf evergreen and/or semi-deciduous forest (tree height $>5 \mathrm{~m}$ ), (2) Closed ( $>40 \%$ ) broadleaf deciduous forest ( $>5 \mathrm{~m}$ ), (3) Open (15-40\%) broadleaf deciduous forest ( $>$ $5 \mathrm{~m}$ ), (4) Closed (> 40\%) needleleaf evergreen forest (>5 m), (5) Open (15-40\%) needleleaf deciduous or evergreen forest $(>5 \mathrm{~m})$.

\subsection{Sap-flow measurements and estimations}

The field campaign was from April 15 to September 25 in 2015 (Julian day of 105268 ) and 2016 (Julian day of 106-269). All trees with $>5 \mathrm{~cm}$ diameter at breast height in the plot were counted within a $400 \mathrm{~m} 2$ sampling plot (good representative of entire tower footprint) for sap-flow measurements situated $100 \mathrm{~m}$ north of the Mohe tower. There were 94 larch and 1 pine, and no birch or aspen in the sampled plot. Sapflow measurements for pines and birches were ignored due to their low abundance. Intraspecies competition (dominant, intermediate, and suppressed) of larch was determined by degrees of canopy dominance (higher tree height with larger canopy area).

A $20 \mathrm{~cm}$ length increment borer (Haglöf, Långsele, Sweden) was used to drill growth cores (bark to pith; in a south to north direction) from 20 randomly selected larches. Sampled cores were dried at $70 \circ \mathrm{C}$ for $48 \mathrm{~h}$ and polished by 240 and 800 sandpaper. LINTABTM linear tree-ring measuring stage (RINNTECH, Heidelberg, Germany) was used for estimating sapwood widths and forest age ( $\sim 51 \mathrm{yr})$ from processed cores. We found that the sapwood area (tissues for water transportation) was tightly correlated with the diameter at breast height, that was fit to a linear law 
(Figure S3d). We selected nine uncored larches (out of 34) for the sap-flow measurement by thermal dissipation probes (details in Supplementary Materials Section 3), and each group of dominant, intermediate, and suppressed trees had three samples. Total magnitudes of transpiration in each class of the plot were upscaled by total sapwood area and sap-flow density ( $E q 1$ and $E q 2)$.

$T_{\delta}=J_{s_{-} \delta} \times \frac{A_{s_{-} \delta}}{A_{G}}, \delta=d, i, s$

where: $T \delta$ is the magnitude of transpiration $\left(\mathrm{mm} \mathrm{h}_{-1}\right)$ in tree classes of dominant $(d)$, intermediate $(i)$, and suppressed (s); $J_{\mathrm{s} \_} \delta$ is sap-flow density of each tree class $(\mathrm{m} 3 \mathrm{~m}-2$ $\left.\mathrm{d}_{-1}\right) ; A_{\mathrm{s}} \delta$ is the total area of sapwood in each tree class; $A_{\mathrm{G}}$ is the plot area (m2); $T_{\text {tot }}$ is the sum of transpiration from all larch classes.

\subsection{Nighttime sap-flow determinations}

As indicated in Figure 2, nighttime sap flow was based on the intensity of environmental driving forces over different phenophases (Fisher et al., 2007). Assumed scenarios including: (a). When nighttime vapor pressure deficit (VPD, the primary driver for transpiration), was near zero, as generally occurred during the cold periods, we assume that any observed sap-flow during night is refilling only. The diel pattern of sap-flow was marked by a rise soon after sunrise, declining with decreasing solar radiation in the evening and tailing off to zero within a couple of hours after sunset (Fisher et al., 2007). (b). When nighttime VPD was elevated, as generally during warm periods, both transpiration and xylem refilling are expected to occur.

Note that Fisher et al. (2007) considered two approaches to analyze the nighttime partitioning: (1) Projected refilling into the transpiration period (yields an upper bound for refilling), and (2) Back-extrapolated transpiration into the refilling period (a lower limit on refilling, upper limit on water loss). Theoretically, refilling water losses should occur together during the transition and the separation will be biased by either abovementioned approach (outlined by dark-grey box in Figure 2 Scenario b). We apply a compromise approach that distinguishes transpiration from xylem refilling based on the time of an inflection point in sap-flow curve rather than extrapolate the curves for each process during the transition. The xylem refilling is subtracted from nighttime sap-flow measurements for analysis and quantification throughout this study unless mentioned specifically. 


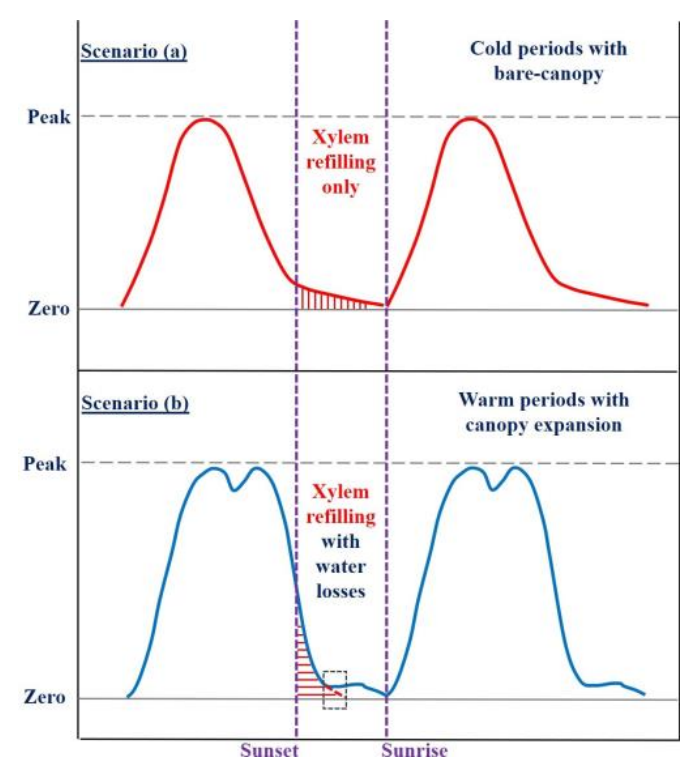

Figure 2. Schematic graphs indicate the scenarios on patterns and determinations of nighttime sap-flows. Red crosshatching indicates the portions of xylem refilling. In scenarios (b), dotted line rectangle highlighted the tail of xylem refilling is under the water loss (overlapped two processes; Fisher et al., 2007).

\subsection{Net water flux measurements}

An integrated three-dimensional sonic anemometer and open-path infrared gas analyzer, the IRGASON (Campbell Scientific, Logan, USA) installed at $36 \mathrm{~m} \mathrm{(24} \mathrm{m}$ above the mean canopy top) at the top of the Mohe tower measured wind velocity, sonic temperature, and water vapor concentrations at $10 \mathrm{~Hz}$. The high-frequency data were stored on CR3000 datalogger (Campbell Scientific, Logan, USA). Raw flux data were processed by the EddyPro (Li-Cor, Lincoln, USA), and a post-processing $R$ package "FREddyPro" (https://www.cran.r-project.org/packages/REddyProc) was applied to verify the reliability of the output data and remove outliers. Energy closure analysis is discussed in the supplementary materials (Figure S4), and the correction of latent heat fluxes followed Mauder et al. $(2007 ; 2013)$ with the Tovi software (Li-Cor, Lincoln, USA).

ET and other fluxes including momentum, sensible heat, and $\mathrm{CO}_{2}$ were calculated from the high-frequency data over 30-minute intervals. Results for carbon flux dynamics are presented in a concurrent study focused on Siberian larch's carbon dynamics (Liu et al., 2019). Axis rotation for tilt correction used the method of planar fit with no velocity bias (van Dijk, 2004). Turbulent fluctuations were calculated by applying the block-averaging method.

Observations under low turbulence situations, which have unrealiable eddy flux values, were also eliminated by the $u^{*}$ threshold (Moving Point Test; Gu et al., 2005). The $\mathrm{u}^{*}$ threshold $(0.13 \mathrm{~m} \mathrm{~s}-1$ at Mohe site) was derived from the entire day but not daytime/nighttime only. Approximately $42 \%$ and $49 \%$ of the total observed fluxes had acceptable $\mathrm{u}^{*}$ values in 2015 and 2016, respectively. Also, it shows that averaged water flux in low turbulence situations is $0.78 \pm 0.23 \mathrm{mmol} \mathrm{m-2} \mathrm{s-1,} \mathrm{while} \mathrm{in} \mathrm{high}$ turbulence situations is $1.23 \pm 0.31 \mathrm{mmol} \mathrm{m}-2 \mathrm{~s}-1$. 
The final flux QA/QC step included manual checks of daily and monthly variations and monthly diurnal-nocturnal distributions of $E T$. Water vapor vertical profiles were not measured, so the storage term for water flux could not be calculated. We estimated a lower limit for the canopy storage by assuming a constant water vapor mixing ratio beneath the IRGASON for deriving the ecosystem ET (Papale et al., 2006). Because the forest canopy and trunk space were fairly open, this assumption was reasonable.

We found the manufacturer's firmware for correcting the spectroscopic effect of the IRGASON's gas analyzer used a slow-response sensor to capture the air temperature, which did not provide enough temporal resolution to accurately correct $\mathrm{CO}_{2}$ concentrations when air temperature was below -1.0 oC (Wang et al., 2016). In place of the standard firmware, we calculated a correction based on the fast-response temperature sensor (sonic anemometer) applied to the individual $10 \mathrm{~Hz} \mathrm{CO}_{2}$ values.

The IRGASON is designed to perform well in high-humidity conditions using innovative features, including: (1) Gas analyzer windows are polished, slanted at an angle, and coated with a hydrophobic material to prevent water from collecting on their surfaces; (2) Wicks are used on the windows to promote capillary action and move water away from the window edges; (3) Heaters in the inlet are turned on to help minimize data loss because of precipitation and condensation events.

\subsection{Microclimate measurements}

Meteorological measurements were made at $35 \mathrm{~m}$ height above the ground. Air temperature and relative humidity were measured using passively-shielded HMP155 probes (Vaisala, Vantaa, Finland). Wind speed was measured using a 010C wind speed sensor (MetOne, Grants Pass, USA). Photosynthetically-active radiation and total net radiation were measured at $23 \mathrm{~m}$ height by a LI190SB (Li-Cor, Lincoln, USA) and an NR01 sensor (Hukseflux, Delft, Netherlands), respectively. Four CS650 integrated soil temperature, moisture and conductivity probes (Campbell Scientific, Logan, USA) were placed into the ground at $5,10,20$, and $40 \mathrm{~cm}$ depths to measure the profile soil temperatures and volumetric soil water contents. Microclimatic measurements were sampled every $5 \mathrm{~min}$ and saved as $30 \mathrm{~min}$ averages by the CR3000 datalogger (Campbell Scientific, Logan, USA).

Site level liquid precipitation was measured at $23 \mathrm{~m}$ height of the tower using a TE525 unheated tipping bucket rain gauge (Campbell Scientific, Logan, USA). However, this single point measurement was likely an underestimate because the solid precipitation (e.g., snowfall, hail, and sleet) was not collected, and wind-blown precipitation was inefficiently sampled (Figure S5). Unless noted otherwise we used the regional precipitation data from the 0.5 o by 0.5 o national precipitation compilations (Data Center of China Meteorological Administration; CMA) to represent the regional condition of precipitation. CMA precipitation was calculated based on ground meteorological stations and upscaled to a $40-\mathrm{km}$ spatial resolution. Also, in this study, rainy days were defined as their daily cumulative precipitation $\geq$ $1.0 \mathrm{~mm}$, and the rest were defined as non-rainy days.

\subsection{Full list of adopted remote sensing data}

In addition to the remote sensed products for land use types and site level geoinformation illustrated in Figure 1 (i.e., GlobCover, DEM, and Landsat TM), we also 
adopted another four satellite products and two publicly released long-term weather datasets, including MODIS leaf area index (LAI; MCD15A3H; Myneni et al., 2015), MODIS fractional snow cover (FSC; MOD10A1; Hall and Riggs, 2016), Global Ozone Monitoring Experiment-2 (GOME-2) SIF (Joiner et al., 2014), MODIS ET (MOD16A2; Mu et al., 2007), Global Precipitation Climatology Project (GPCP) monthly precipitation dataset (Adler et al., 2003), and Berkeley Earth monthly averaged/bias-corrected air temperature (Rohde et al., 2003). Moreover, MODIS products showed in this study were all pre-processed by The Oak Ridge National Laboratory Distributed Active Archive Center (https://daac.ornl.gov/). GOME-2 SIF in the study was normalized by the solar zenith angles (method described by Luus et al., 2017).

Moreover, phenophase in boreal larch forest is determined by the curvature-change model using the MODIS LAI (Zhang et al., 2003). Specifically, transition dates correspond to the time at which the curvature values exhibit local minima or maxima. During greenness, the two maximum values correspond to the onset of greenness increase (leaf-onset) and the onset of greenness maximum (leaf full-expansion). Similarly, during periods of LAI decrease the two minimum values identify the onset of greenness decrease (leaf-senescence) and the onset of greenness minimum (leafdormant). The confidence limits (s.d.) of the season lengths and transition days was estimated by using Monte-Carlo simulations. Based on fitted parameters of curvaturechange model, we ran 500-times permutations of these random variables to calculate all possible outcomes of the transition dates. Note that s.d. is considered if the difference between length of greenness periods across 2015 and 2016 is significant or still within the uncertainty and time resolution of the MODIS LAI derived transition dates.

\subsection{Machine learning prediction of water fluxes}

In order to integrate flux observations to the longer time intervals needed for evaluating water and carbon budgets, gaps introduced by instrument downtime and invalid measurements must be filled in. Machine learning has been well developed for predicting ET since the early-2000s (Whitley et al., 2009; Mehdizadeh, 2018). In this study, we adopted RandomForest for the gap-filling (Breiman, 2001). RandomForest is originally designed for purposes of ecological classifications (Cutler et al., 2007), while its full application to the ecological regressions evolved afterward by others (Iverson et al., 2007; Labrière et al., 2016; Schwalm et al., 2017). RandomForest constructs multiple trees (i.e., information assembled clusters) individually, and each tree grows with a randomized subset of predictor variables and further yields predictions independently. Afterward, all decisions will be aggregated and then averaged to produce the final predictions. More importantly, RandomForest possesses good data economy and performances, especially in dealing with the less computationally intensive tasks or smaller datasets (e.g., usually 35\% gaps in flux measurements; Falge et al., 2001).

RandomForest calculations were perfomed in $R$ (RandomForest package; https://www.cran.r-project.org/web/packages/randomForest/). Motivated by the parameters that represent energy exchange, atmospheric turbulence, and ambient 
water supply in the Penman-Monteith equation (Sun et al., 2014; Sun et al., 2016), we selected the following fundamental variables (e.g., directly measured) to train the algorithm: (1) Net radiation, air temperature, and soil temperature, which reflect energy distributions and changes; (2) Wind speed and relative humidity, which reflect the atmospheric turbulence above the canopy; (3) Soil water content, which reflects the available water resource from the ground level. Only the fundamental variable is accepted, because the function-based variables (e.g., vapor pressure deficit versus temperature and humidity) will affect machine learning's decision on speculating their functional relationships and result in the overfitting (Schaffer, 1993).

Observed ET in 2015 and 2016 ( $n=13$ 408; excluded 4038 gaps) was randomly divided into non-duplicated training dataset $(n=7500)$ and evaluation dataset $(n=$ 3500). The training dataset was input for RandomForest. Evaluation dataset was kept for verifying the functionality of RandomForest predictions. Settings and summary statistics for the RandomForest simulation are given in Table 1. The following evaluations concluded that RandomForest was an ideal solution for the predictions of $E T$ in boreal larch forest (adjusted $r 2=0.97 \pm 0.01$; Figure $3 \mathrm{a}$ ). Though the peakvalues of $E T$ were slightly underestimated by the algorithm, the overall seasonal patterns were still well simulated (Figure 3b).

Table 1. Statistics on the eigenvalues of RandomForest simulation. Note that the statistics on the bottom of table were based on a 7500 sized training dataset. Abbreviations of ntree and mtry represent the number of trees and the number of variables per level, respectively. Unit of root mean square error (RMSE) is in mmol $\mathrm{m}-2 \mathrm{~s}-1$. OOB is the out of bag error rate, representing the proportion of data that are not used for the individual regression tree-model building. Mean decrease in Accuracy (MDA) and mean decrease in Gini index (MGI) are two importance scores output from the RandomForest algorithm, in short, the larger the value, the more significant the result is. Abbreviations of $T_{\mathrm{s}}, \mathrm{SWC}, R$ net, $W S, T \mathrm{a}$, and $R H$ are soil temperature at 5 $\mathrm{cm}$ depth, weighted volumetric water content (from 5 and $40 \mathrm{~cm}$ depths), upper canopy total net radiation, upper canopy wind speed, upper canopy air temperature, and upper canopy relative humidity, respectively.

\begin{tabular}{ccccccc}
\hline \multirow{2}{*}{$\begin{array}{c}\text { Preferences and } \\
\text { statistics }\end{array}$} & No. of training data & No. of gap-filled & No. of ntree & No. of mtry & RMSE & OOB \\
\cline { 2 - 7 } & 7500 & 4038 & 1000 & 2 & 0.62 & 0.44 \\
\hline \hline Importance scores & $T_{\mathrm{s}}$ & SWC & $R_{\text {net }}$ & WS & $T_{\mathrm{a}}$ & $R H$ \\
\hline MDA & 0.48 & 0.28 & 2.21 & 0.21 & 0.47 & 0.27 \\
\hline MGI & 1379.7 & 1005.7 & 7415.1 & 1160.5 & 2340.8 & 1221.7 \\
\hline
\end{tabular}




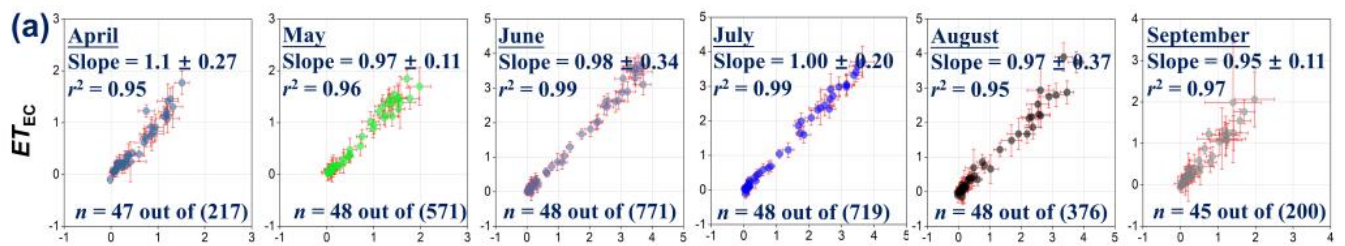

(b)

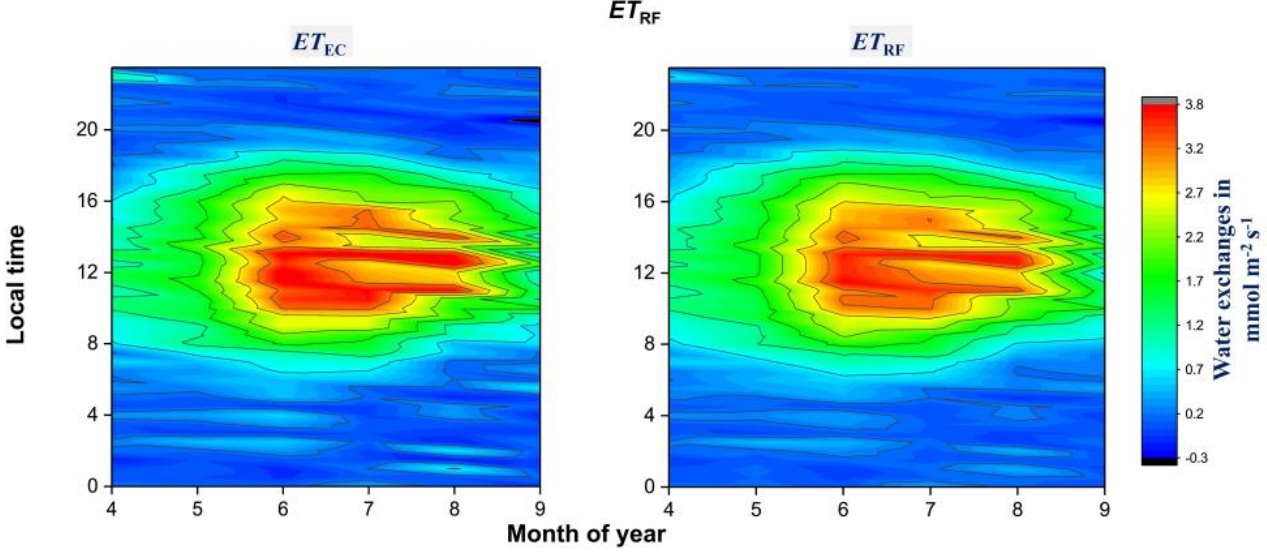

Figure 3. Evaluations on the RandomForest predicted $E T\left(E T_{\mathrm{RF}}\right)$ by the tower observation $\left(E T_{\mathrm{EC}}\right)$ with a 2500 sized dataset. Data in panels (a) and (b) are aggregated between 2015 and 2016. In panel a: samples $n$ are binned from a data clusters (size showed in parentheses) by the time of day with the format of median \pm s.e. Also the uncertainties (s.e.) of linear slopes are showed in each regression plots. Different filling colors indicate data periods (e.g. the month).

\section{Results}

\subsection{Microclimates in China's boreal larch forest}

Generally, the climate in the southern edge of Siberia is influenced by the semipermanent continental Siberian Anticyclone, which keeps the region cool and dry. The continuous permafrost at Mohe site thaws to a depth of 50-100 cm (shallower on shady slopes and deeper on sunny slopes) by the end of summer, which is within the range $(50-110 \mathrm{~cm})$ for zonal permafrost thaw depths monitored at a boreal site near the southern Greater Hinggan Mountain $(50 \mathrm{o} N)$ and a Central Siberian boreal site (56o $\mathrm{N}$; Figure S6).

A total of 328 days field observations (from April 15 to September 25 with 164 days of each year) were included in this study (Figure 4). No observations were made for the remaining periods when solar power was insufficient, and site access was challenging due to the harsh weather. As highlighted in Figure 5h, differences in precipitation patterns and total accumulation for the observed periods were very obvious between 2015 (409.9 mm) and 2016 (743.5 mm). Precipitation in 2015 was dominated by events yielding $<1 \mathrm{~mm} \mathrm{~d}-1$, while precipitation intensity in 2016 was shifted towards larger events (Figure S5). Total annual precipitation of $510.2 \mathrm{~mm}$ in 2015 was similar to the regional mean precipitation of $460.8 \mathrm{~mm}$ (1959-2017), while 2016 with $792.1 \mathrm{~mm}$ was an anomalously wet year. Also, we observed the 2016 anomaly is among the top three precipitation extremes in the entire data records.

Precipitation links closely to patterns of air temperature and VPD (Figure S7). The heavier precipitation at Mohe in 2016 was part of a larger scale precipitation anomaly 
that was identified by GPCP (Figure 5). So that, consistency of GPCP and CMA precipitation anomaly in 2016 highlighted this precipitation excess is a regional feature and not just local to Mohe (Figure 5a, Figure S5). Precipitation and temperature anomalies were more frequent since 2002 . The precipitation anomaly was slightly lagged behind the temperature anomaly (Figure 5a, c). Taken together, precipitation patterns in Mohe site, in particular during the growing season, were closely related to the local temperature (Figure 5e), as the warm air masses carry moisture and synoptic weather patterns affect them together.

Each year was divided into four canopy-phenophases of leaf-dormancy, leaf-onset, full leaf expansion, and leaf-senescence based on the MODIS LAI (Figure 4f). The growing season length (from leaf-onset to leaf-senescence) in 2015 was $111( \pm 3.3$; s.d.) days and was extended to $120( \pm 4.7)$ days in 2016, where this extension was due to longer leaf-onset and leaf-senescence phenophase instead of the shorter leaf-fullexpansion compared to 2015 . The main meteorological variables were significantly different between the phenological stages (Table S2).

2015 starts with wet soil but dries over summer, and enters dormant season still dry until thaw and new precipitation saturate the soil in 2016 spring (Figure 4e). Soil moisture in 2016 recharged quickly from its dry condition to near saturation following heavy rain on the day of year 112 that fell on the melting snowpack (Figure 4g). Except for the dry period in dormant phenophase of 2016 soil moisture in the remainder of both years was at or above the field capacity. 


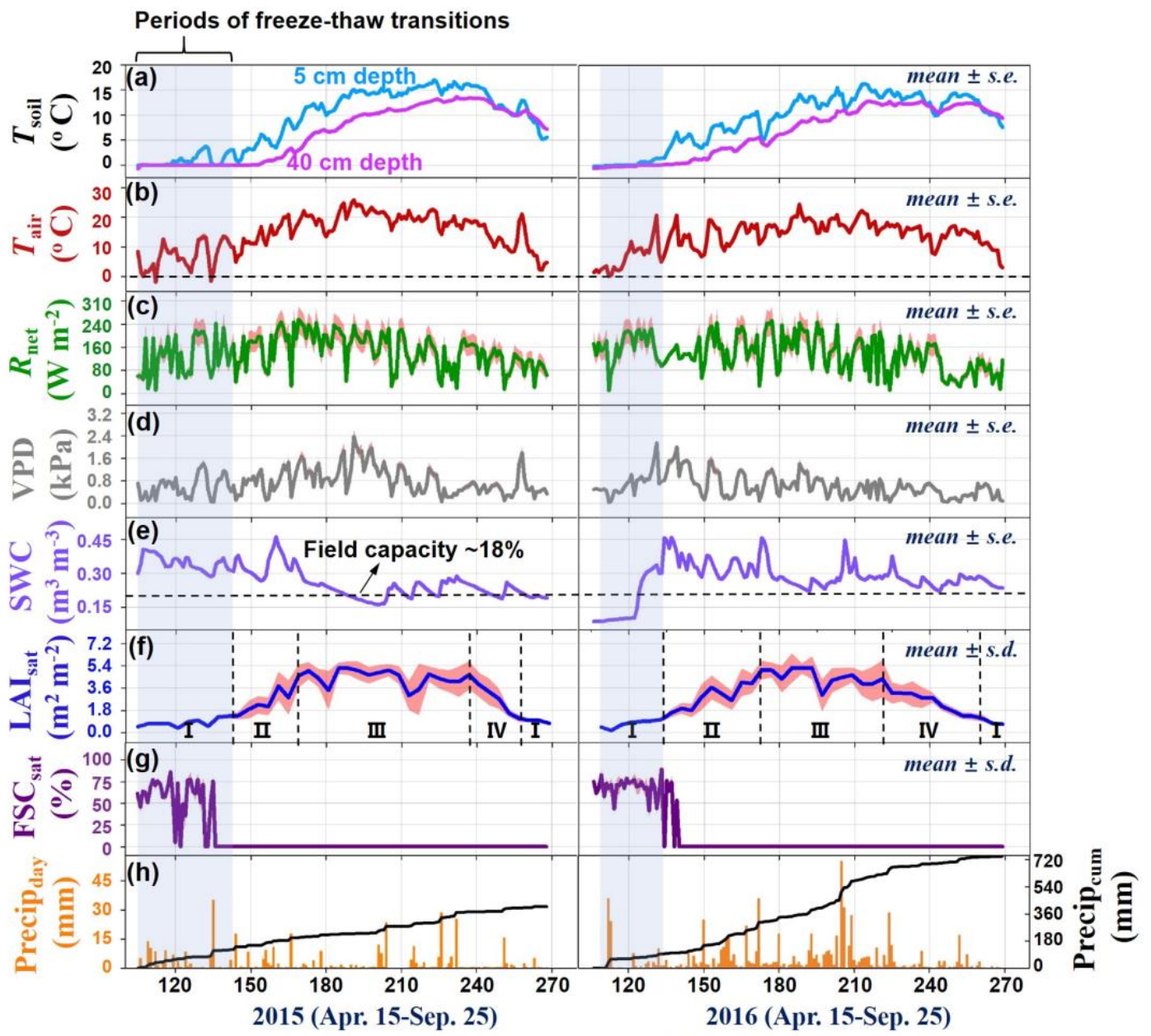

470

471

472

473

474

475

476

477

478

479

480

481

Julian day number

Figure 4. Time series of microclimatic variables during two-years field campaigns.

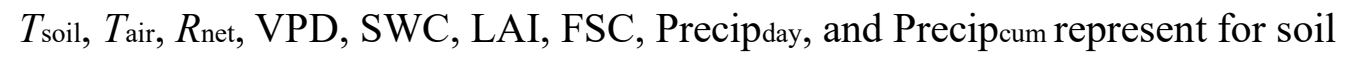
temperature, air temperature, total net radiation, vapor pressure deficit, weighted soil water content ( 5 and $40 \mathrm{~cm}$ depths), satellite leaf area index, satellite fractional snow cover, daily precipitation, and cumulative precipitation, respectively. I, II, III, and IV with the dashed line in panel (f) identify the four canopy phenophases, i.e., leafdormant, leaf-onset, leaf full-expansion, and leaf-senescence, respectively. The leaf dormant period is additionally identified by gray shading. The black dashed line in panel (e) indicates field capacity in boreal larch forest measured during growing season of 2015. MODIS LAI and FSC were both retrieved with $2.5 \mathrm{~km}$ by $2.5 \mathrm{~km}$ pixels by centered on the Mohe flux tower. FSC was smoothed using a $R$ loess filters. 

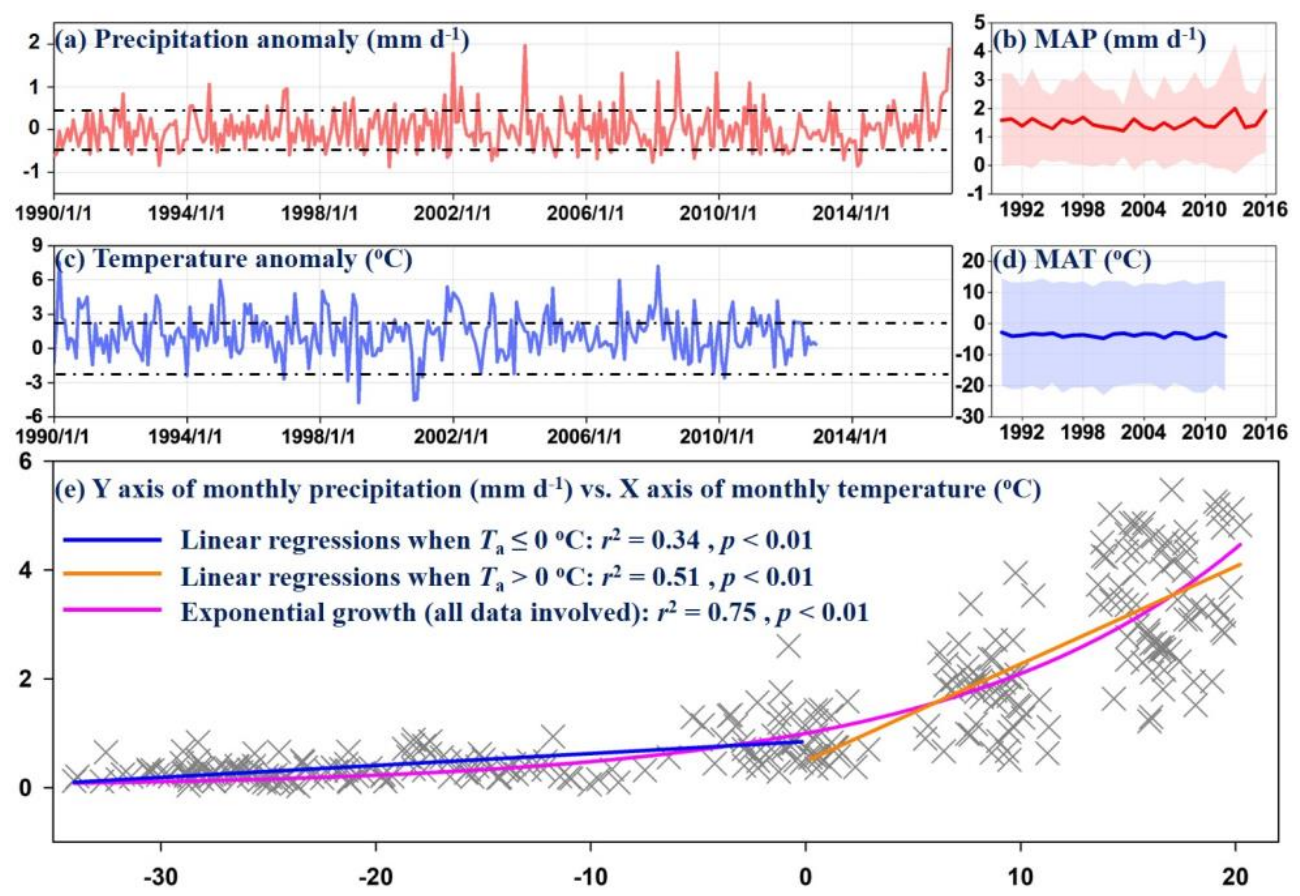

Figure 5. Panels (a)-(b): Monthly precipitation anomalies and annual mean precipitation rates given by GPCP precipitation for the $2.5^{\circ}$ by $2.5^{\circ}$ grid surrounding Mohe (Adler et al., 2003) are shown for 1990-2016. Panels (c)-(d): Monthly temperature anomalies and mean annual temperature rates from the Mohe station given in Berkeley Earth air temperature dataset are shown for 1990-2012. Panel (e): Monthly precipitation against monthly temperature for periods of 1990-2012. Anomalies are computed by calculate the long-term mean from the 1990-2016 data, and then subtracting the overall mean from the data for a given month and year. Throughout the text, we consider abnormal climate events to be those years in which temperature or precipitation anomalies exceed 0.5 s.d. (black dashed lines) of the interannual temperature or precipitation variabilities (Diffenbaugh et al., 2015).

\subsection{Nighttime sap-flow separation of boreal larch forest}

We observed sap-flow fluctuations at the end of dormant phenophase (day of year 142 in 2015 and 133 in 2016) prior to the leaf-out suggesting that sap transport supports metabolism in unopened buds (Figure S8). Nighttime sap-flows primarily responded to nighttime above-canopy VPD. The influence of nighttime above-canopy air temperature was minimal (Figure S9). Also, we found that dominant larch was more sensitive to environmental conditions, as measured above the canopy, than the intermediate and suppressed larch that are in the subcanopy.

The separation of the nighttime sap-flow was run for the entire dataset and then visualized by taking four-day data sequences as examples (Figure 6). Boreal larch forest usually needs four hours to refill the xylem water deficit after the intense daytime water losses during non-dormant phenophase. By our definitions (described in Section 2.3), nighttime sap-flows can be numerically distributed into xylem refilling and real water losses. So that the larger proportion of xylem refilling, the smaller percentage of water losses. We quantified the xylem refilling in dominant larch groups, which constituted $95 \%$ of integrated nighttime sap-flows (i.e., $5 \%$ real 
water losses). While for intermediate and suppressed larches, xylem refilling accounted only for $80 \%$ (20\% water losses). These 5\%-20\% nighttime water losses equaled to approximately $2 \%-9 \%$ of total daily transpiration. The smaller proportion of xylem refilling in intermediate and suppressed larches indicated that being in the shade protected these trees from drying by direct radiation and may have reduced the VPD they were exposed to.

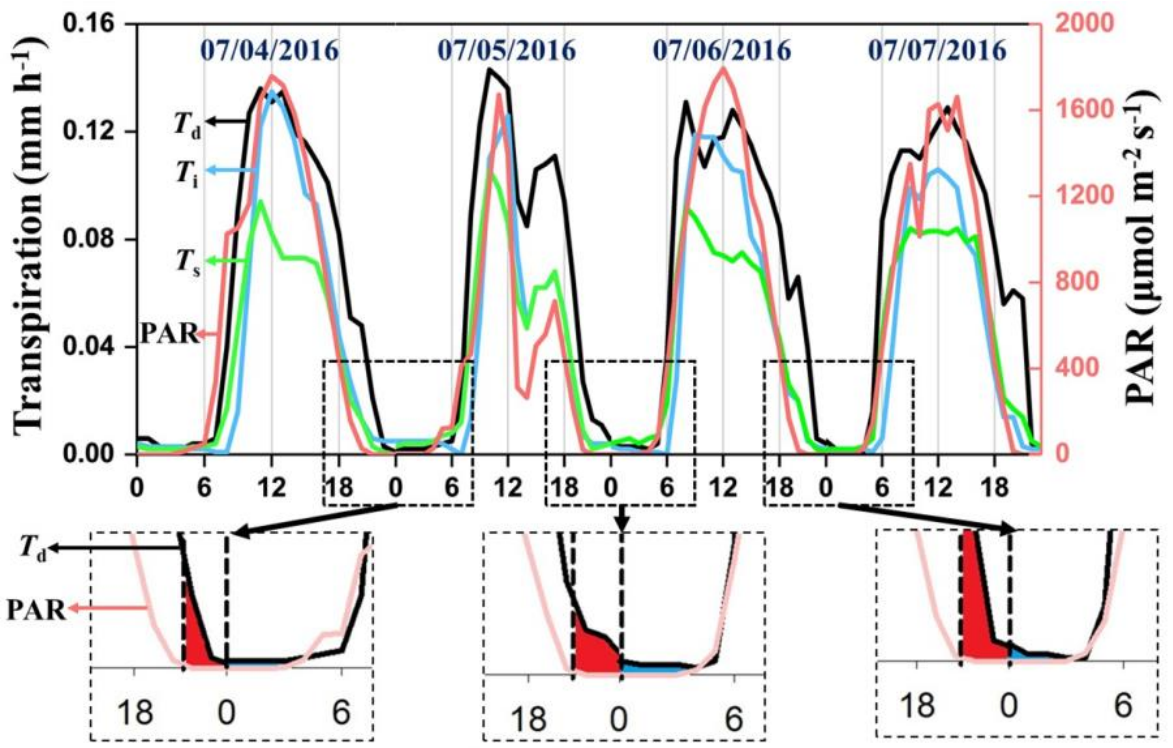

Local time (UTC+8)

Figure 6. Snapshot of nighttime sap-flow separation during the growing season. Patterns of sap-flow were primarily controlled by changes in vapor pressure deficit (Figure S9). The set of images across the lower portion of the panel focus on the nocturnal periods identified by shading. Xylem refilling and water losses are shown by the red and blue shading, respectively. Determination approach explained in Section 2.3.

\subsection{Precipitation and phenology regulate water fluxes}

Variations of precipitation, phenophase and their interactions influenced water fluxes in boreal larch forest (Table 1). We applied principal component analysis to identify the dominant variables (out of 11 possible measurements) that would be considered in the microclimatic regulation analysis (Table S3). The first principal component accounted for $40.4 \%$ of the total variance. The variables that correlated the most with the first principal component were air temperature $(0.62)$, vapor pressure deficit (0.53), surface soil temperature (0.45), and net radiation (0.45).

Different levels of annual precipitation input could modify the effect of microclimate on water fluxes (Figure S10). For instance, ET was significantly controlled by soil temperature in both 2015 (normal year) and 2016 (the wetter year). While transpiration was only influenced by soil temperature in the normal year. On the other hand, the evaporation which includes contributions from canopy interception, forest floor, exposed soil, and any surface water, calculated as difference between $E T$ and transpiration, was related to soil temperature in the wetter year but not in the normal year. 
The principal component results were corroborated by stepwise regressions (Table

540 2). The stepwise regression further highlighted that transpiration of three larch canopy

541 classes responded differently to microclimate. Excess precipitation introduced

542 uncertainty to the prediction of transpiration (e.g., overall lower $r 2$ in the wetter year).

543 Also, we found transpiration would increase with VPD (positive signs) because of

544 increased atmospheric demand.

545 In general, analysis revealed that, air temperature, net radiation, and VPD are

546 primary controllers of biotic hydrological processes (e.g., transpiration) in this boreal

547 larch ecosystem. It is a common recognition that forest $E T$ and transpiration are

548 controlled strictly by air temperature, net radiation, and VPD (Law et al., 2002;

549 Motzer et al., 2005; Mackay et al., 2007). Furthermore, we saw controls by VPD were

550 even stronger in the year with precipitation extremes, while the influence of air

551 temperature and net radiation declined when water availability was in excess. Shifting

552 of inter-annual precipitation patterns will introduce uncertainties into correlations

553 between forest hydrology and climatic drivers (Trenberth, 2011; Endo et al., 2017). 
Table 1. An analysis of variation procedure with tower and repeated sap-flow measurements and the Tukey's Honestly Significant Difference test here to analyze the fixed effects of phenophase, precipitation, observational years, and their interactions on water flux components. Formula of $\operatorname{glm}()$ function in $R$ : 'WFC phenophase + precipitation + year', where WFC is water flux component listed below. $T_{\mathrm{d}}, T_{\mathrm{i}}, T_{\mathrm{s}}, T_{\mathrm{tot}}$ and $E T$ represent transpiration from dominant trees, intermediate trees, suppressed trees, ecosystem transpiration fluxes, and ecosystem evapotranspiration, respectively. $D f$, Adj SS, Adj MS are degrees of freedom, the adjusted sum of squares, and the adjusted mean sum of squares, respectively. Statistical terms (in particular the interactions) that were not significant in the final model do not appear in the table.

\begin{tabular}{|c|c|c|c|c|c|c|}
\hline Component & Effect & $d f$ & Adj SS & Adj MS & $F$ & $P$ \\
\hline \multirow{6}{*}{$T_{\mathrm{d}}$} & Phenophase & 3 & 10.571 & 3.524 & 13.99 & 0.000 \\
\hline & Precipitation & 1 & 2.664 & 2.664 & 10.57 & 0.001 \\
\hline & Year & 1 & 3.486 & 3.486 & 13.84 & 0.000 \\
\hline & Pheno $\times$ Year & 3 & 1.957 & 0.652 & 2.59 & 0.053 \\
\hline & Precip $\times$ Year & 1 & 1.321 & 1.321 & 5.24 & 0.023 \\
\hline & Residuals & 317 & 79.854 & 0.252 & & \\
\hline \multirow{5}{*}{$T_{\mathrm{i}}$} & Phenophase & 3 & 6.481 & 2.160 & 26.57 & 0.000 \\
\hline & Precipitation & 1 & 1.124 & 1.123 & 13.82 & 0.000 \\
\hline & Year & 1 & 0.178 & 0.178 & 1.69 & 0.194 \\
\hline & Precip $\times$ Year & 1 & 0.333 & 0.333 & 4.09 & 0.044 \\
\hline & Residuals & 320 & 26.022 & 0.081 & & \\
\hline \multirow{6}{*}{$T_{\mathrm{s}}$} & Phenophase & 3 & 5.015 & 1.672 & 29.47 & 0.000 \\
\hline & Precipitation & 1 & 0.536 & 0.536 & 9.44 & 0.002 \\
\hline & Year & 1 & 0.314 & 0.314 & 5.54 & 0.019 \\
\hline & Pheno $\times$ Year & 3 & 0.776 & 0.259 & 4.56 & 0.004 \\
\hline & Precip $\times$ Year & 1 & 0.314 & 0.314 & 5.53 & 0.019 \\
\hline & Residuals & 317 & 17.985 & 0.057 & & \\
\hline \multirow{5}{*}{$T_{\text {tot }}$} & Phenophase & 3 & 73.609 & 24.536 & 24.86 & 0.000 \\
\hline & Precipitation & 1 & 14.332 & 14.332 & 14.52 & 0.000 \\
\hline & Year & 1 & 4.497 & 4.4974 & 4.56 & 0.034 \\
\hline & Precip $\times$ Year & 1 & 4.535 & 4.5355 & 4.60 & 0.033 \\
\hline & Residuals & 320 & 315.775 & 0.987 & & \\
\hline \multirow{5}{*}{ ET } & Phenophase & 3 & 225.361 & 75.120 & 75.48 & 0.000 \\
\hline & Precipitation & 1 & 17.580 & 17.576 & 10.40 & 0.001 \\
\hline & Year & 1 & 3.070 & 3.070 & 3.08 & 0.030 \\
\hline & Pheno $\times$ Year & 3 & 10.201 & 3.400 & 3.42 & 0.018 \\
\hline & Residuals & 318 & 316.501 & 0.995 & & \\
\hline
\end{tabular}

Table 2. Stepwise regression analysis of water flux with microclimatic variables across 2015 and 2016. Microclimatic variables were selected by the PCA analysis (Table S3). $\sigma$ indicates uncertainties of each coefficient. $N A$ represents no corresponding parameter involved.

\begin{tabular}{llccccccc}
\hline Year & Regression equation & $\boldsymbol{\sigma} \mathbf{T}_{\text {soil }}$ & $\boldsymbol{\sigma} \mathbf{T}_{\text {air }}$ & $\boldsymbol{\sigma} \boldsymbol{R}_{\text {net }}$ & $\boldsymbol{\sigma}$ VPD & $\boldsymbol{r}^{2}$ & $\boldsymbol{F}$-value & $\boldsymbol{p}$-value \\
\hline & $T_{\mathrm{d}}=0.12+0.02 T_{\text {soil }}+0.00 R_{\text {net }}+0.49 \mathrm{VPD}$ & 0.03 & $N A$ & 0.01 & 0.17 & 0.85 & 294.2 & 0.00 \\
& $T_{\mathrm{i}}=-0.17+0.01 T_{\text {soil }}+0.02 T_{\text {air }}+0.00 R_{\text {net }}+0.09 \mathrm{VPD}$ & 0.02 & 0.01 & 0.00 & 0.01 & 0.92 & 452.6 & 0.00 \\
& $T_{\mathrm{s}}=-0.06+0.01 T_{\text {air }}+0.00 R_{\text {net }}+0.09 \mathrm{VPD}$ & $N A$ & 0.07 & 0.05 & 0.12 & 0.89 & 413.2 & 0.00 \\
& $E=0.49-0.04 T_{\text {soil }}+0.09 T_{\text {air }}-1.35 \mathrm{VPD}$ & 0.07 & 0.11 & $N A$ & 0.28 & 0.20 & 13.22 & 0.00 \\
& $E T=0.28+0.11 T_{\text {sir }}+0.01 R_{\text {net }}-0.72 \mathrm{VPD}$ & $N A$ & 0.08 & 0.00 & 0.57 & 0.62 & 87.5 & 0.00 \\
\hline & $T_{\mathrm{d}}=-0.11+0.02 T_{\text {air }}+0.00 R_{\text {net }}+0.32 \mathrm{VPD}$ & $N A$ & 0.01 & 0.06 & 0.21 & 0.67 & 103.3 & 0.00 \\
& $T_{\mathrm{i}}=-0.29+0.02 T_{\text {soil }}+0.00 R_{\text {net }}+0.32 \mathrm{VPD}$ & 0.03 & $N A$ & 0.00 & 0.18 & 0.81 & 215.6 & 0.00 \\
$T_{\mathrm{s}}=-0.13+0.01 T_{\text {air }}+0.00 R_{\text {net }}+0.34 \mathrm{VPD}$ & $N A$ & 0.07 & 0.12 & 0.27 & 0.74 & 145.9 & 0.00 \\
& $E=0.17+0.11 T_{\text {soil }}+0.01 R_{\text {net }}-1.16 \mathrm{VPD}$ & 0.08 & $N A$ & 0.09 & 0.78 & 0.47 & 45.9 & 0.00 \\
& $E T=-0.34+0.16 T_{\text {soil }}+0.02 R_{\text {net }}$ & 0.12 & $N A$ & 0.00 & $N A$ & 0.66 & 152.9 & 0.00 \\
\hline
\end{tabular}

\subsection{Patterns and partitioning of water fluxes}


As seen in Figure 7a-d, the Mohe site forest exchanged $491.6 \pm 133.4$ (95\% CI) $\mathrm{mm}$ of water by $E T$ in 2015 , including $415.1 \pm 82.1 \mathrm{~mm}$ as transpiration (where $T_{\mathrm{d}}=$ $221.7 \mathrm{~mm}, T_{\mathrm{i}}=96.6 \mathrm{~mm}$, and $T_{\mathrm{s}}=96.9 \mathrm{~mm}$ ) and $76.47 \pm 51.3 \mathrm{~mm}$ as evaporation. $\mathrm{In}$ 2016, ET, transpiration, and evaporation were $529.4 \pm 146.9 \mathrm{~mm}, 350.5 \pm 101.3 \mathrm{~mm}$ (in which $T_{\mathrm{d}}=178.7 \mathrm{~mm}, T_{\mathrm{i}}=88.4 \mathrm{~mm}$, and $T_{\mathrm{s}}=83.4 \mathrm{~mm}$ ), and $178.9 \pm 45.6 \mathrm{~mm}$, respectively. Evaporation was influenced by the soil to atmosphere vapor pressure gradient. The positive soil to air vapor pressure gradient promotes water evaporation, while negative gradients (particularly in the spring when the air warms faster than the soil (see Figure 4 a-b) impedes evaporation or even cause condensation at the soil surface (dew). For example, we occasionally observed the negative evaporation of 2015 (indicating water moves from atmosphere towards the ecosystem; Table S4) during the leaf-dormant and leaf-onset periods, which is the result of the negative gradient (Figure 7c).

Despite the considerable increase in precipitation for 2016, ET for 2016 was only marginally greater than in 2015 (Figure 7e-f; $F_{1,325}=2.96, p=0.09$ ). Evidently, increased precipitation is not promoting a higher ET. In both years, ET sums were mostly comparable to potential evapotranspiration sums (2015: $F_{1,325}=510.83, p=$ 0.04; 2016: $F_{1,325}=601.89, p=0.06$ ), indicating $E T$ is energy limited but not water limited. Together, these results suggested that the ecosystem stored enough water to support all ET demands that could occur and rarely if at all was ET suppressed by lack of available moisture. Again, note that totals of water fluxes in this study are not from the full year, so the water deficits that occur are only in periods from April to October (when we had field observations). But the year-round water deficits can be balanced by winter snowpack. On average winter snowpack is up to $30 \%$ of the annual precipitation $(<138 \mathrm{~mm})$. Also, field observations during some dry anomalous years are needed in the future to test if water availability is ever limiting at this site.

Figure 8a shows that transpiration by dominant larch accounted for at least $50 \%$ of total ecosystem transpiration, while the remainder was almost equally split between intermediate and suppressed larches. To examine the direct influence of precipitation we binned the data into rainy and non-rainy days. ET magnitude increased on the rainy days (Figure $8 b-c$ ). But transpiration had a distinctly lower contribution on rainy days. Either increased evaporation of intercepted precipitation in the canopy or suppression of transpiration by reduced VPD, temperature, and solar radiation associated with rainy weather (or both together) account for the shift in ET partitioning.

ET partitioning is also affected by phenology. During the full leaf expansion phenophase when LAI was at its peak and active photosynthesis requires maximum stomatal opening, transpiration accounted for a larger fraction of ET. During the early growing season before larch needles were fully expanded, but foliage was present in understory shrubs and scattered evergreen conifers, transpiration contributed a large fraction to ET on non-rainy days (Figure $8 \mathrm{~b}$ series). Even though there is abundant standing water at the surface and sunlight penetrates to the ground, evaporation is suppressed in this season because the temperature of those wet surfaces is maintained below the dewpoint by soil frost below (see Figure $4 \mathrm{a}-\mathrm{b}$, Figure $7 \mathrm{c}-\mathrm{d}$ ). 

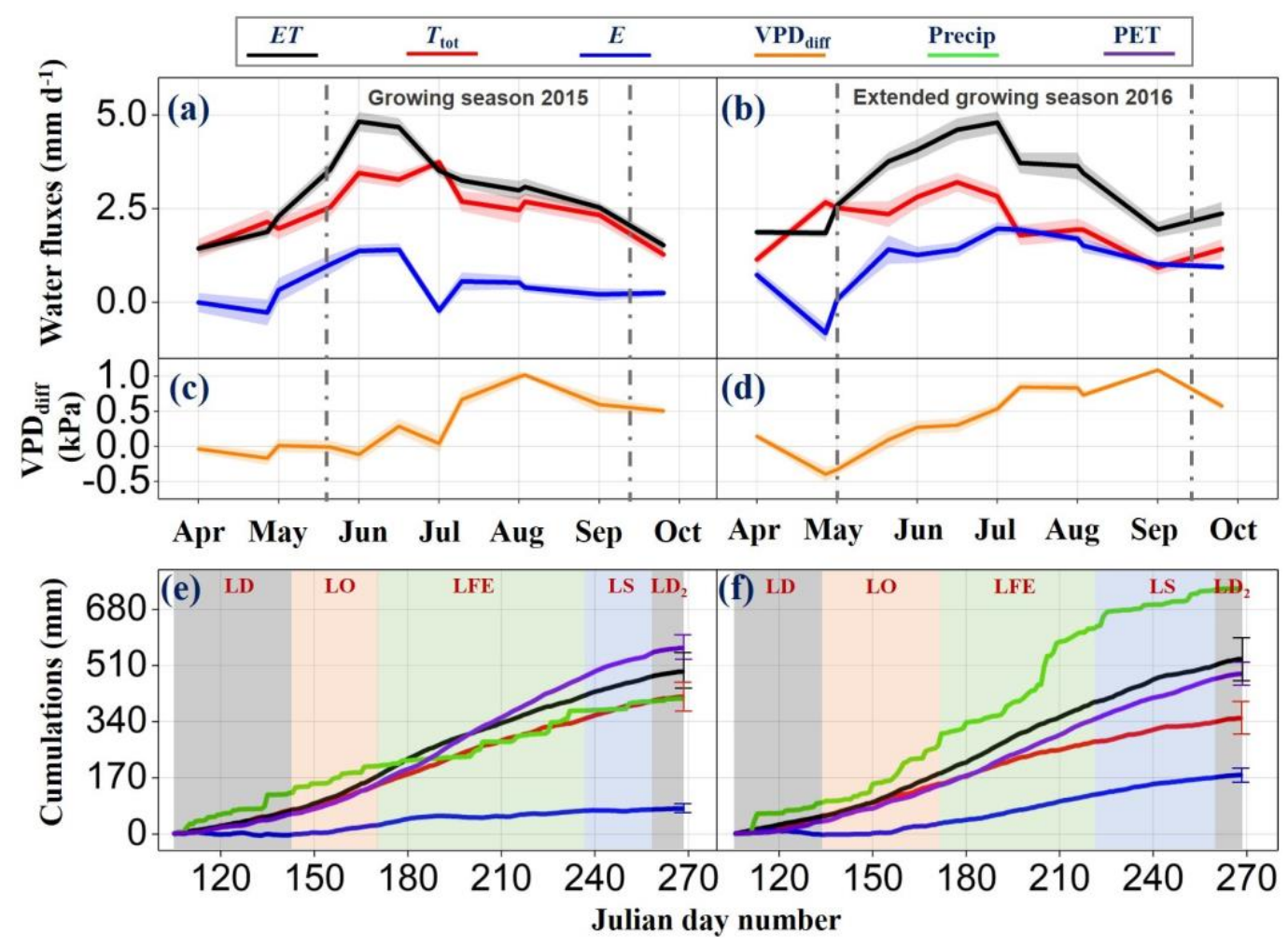

Figure 7. Panel (a)-(d): time-series variations of $E T$, total transpiration ( $\left.T_{\text {tot }}\right)$, and evaporation $(E)$ and vapor pressure gradient between soil and air (VPD diff) in 2015 and 2016. Panel (e)-(f): Cumulative water flux components precipitation and potential evapotranspiration (PET) through 2015 and 2016 observation period. Evaporation ( $E$ ) derived from difference between $E T$ and $T$ tot, where $T$ tot comprises transpiration from dominant $\left(T_{\mathrm{d}}\right)$, intermediate $\left(T_{\mathrm{i}}\right)$, and suppressed $\left(T_{\mathrm{s}}\right)$ trees. Lines connect the mean values \pm s.e. of the biweekly bin (panel a-d), and cumulative sums were derived from daily values (panel e and f). 95\% CI was given at the end of each cumulative by colored +/- segments. Growing season marked with vertical grey dashed lines throughout panel (a)-(d). Leaf-dormant (LD), leaf-onset (LO), leaf fullexpansion (LFE), and leaf-senescence (LS) identified with shaded color backgrounds in panel (e) and (f). PET (purple lines)is the amount of evaporation and transpiration that would occur if a sufficient water source were available (estimated by the Thornthwaite equation in $R$ package 'SPEI'; http://sac.csic.es/spei). Snapshots of interannual dynamics of daily observed water fluxes and VPD soil are shown in Figure S11. 


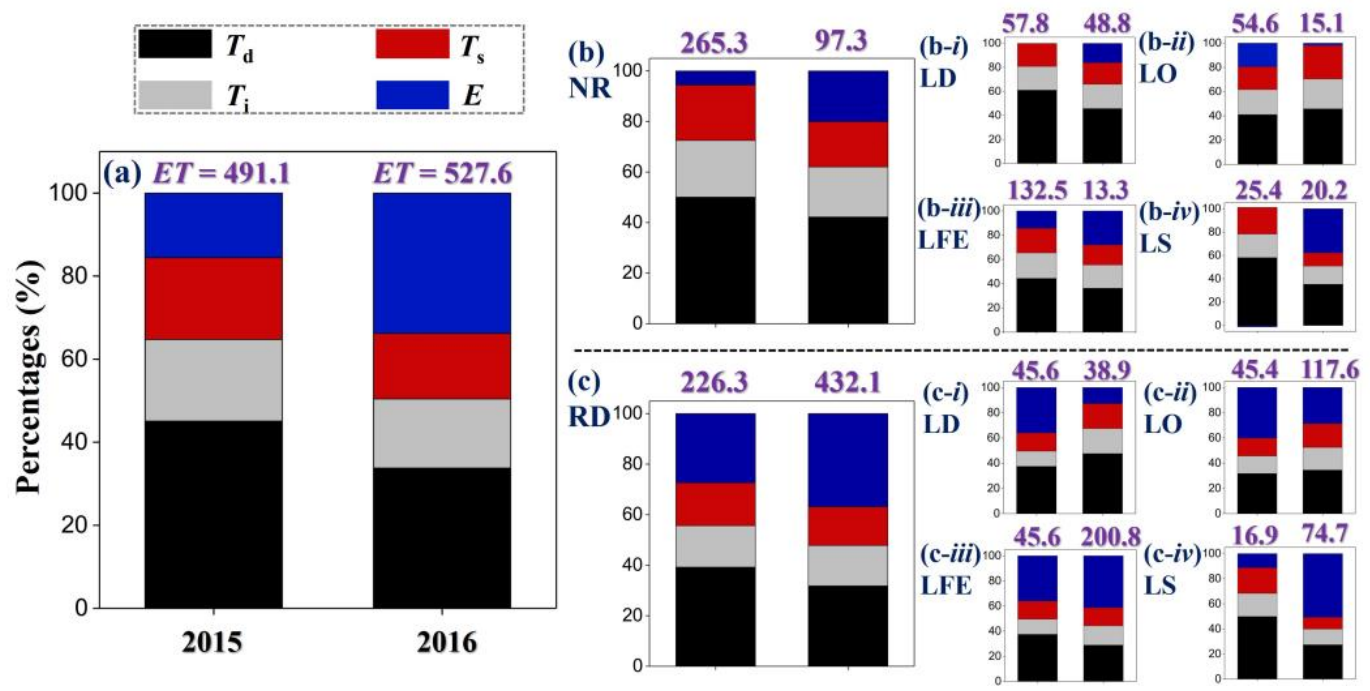

Figure 8. ET partitioning among the tree-size classes and evaporation in 2015 (left columns) and 2016 (right columns) for all data (panel a) and binned according to presence/absence of rain (daily rain $\geq 1 \mathrm{~mm}$ ) (panel $\mathrm{b}$ and $\mathrm{c}$ ), and by phenophase (b-i, $\mathrm{b}-i v$ and $\mathrm{c}-i, \mathrm{c}-i v)$. NR and RD are non-rainy days and rainy days respectively. LD, LO, LFE, and LS are phenophase of leaf-dormant (including both LD and LD2 showed in Figure 7e), leaf-onset, leaf full expansion, and leaf-senescence. The overall magnitude of $E T(\mathrm{~mm})$ for each data subset is given by the number above the partitioning column.

\subsection{Estimates of water flux from remote sensing observations}

To evaluate the influence of spatial variability, we aggregated the MODIS ET values over different spatial scales from single pixel $(0.5 \mathrm{~km})$, through larger regions covering $10 \mathrm{~km}, 20 \mathrm{~km}$, and $40 \mathrm{~km}$ surrounding the tower location. Spatial aggregation did not change the seasonal pattern appreciably (Figure S12a, b). Cloud screening introduces frequent data gaps in the $500 \mathrm{~m}$ MODIS ET that was retrieved from the single pixel surrounding the tower (e.g., Table S5). In particularly note the gaps during leaf-full-expansion period of 2016. Unless otherwise specified all comparisons of ET observations and remote-sensing-based estimates will use the 40 $\mathrm{km}$ aggregation to smooth out variability and reduce the influence of cloud gaps.

In 2015, MODIS ET provided agreed with ET measured at the tower during the growing season (Figure 9a). But in 2016, MODIS ET underestimated ET over the entire growing season (Figure 9b). Pixel quality is negatively correlated with precipitation (Table S6), and the percentage of MODIS pixels that passed QA/QC was reduced in 2016 compared to 2015 (Figure S12d). We also observed decreased accuracy of MODIS ET for each studied year especially during dormant seasons. Snow reflectance and clouds are known issues that compromise the reflectance measurements that MODIS ET is based on. When many pixels in are rejected for cloud contamination, the remaining pixels may not be as representative of the tower; in particular persistent weather patterns could result in the cloud-free pixels having less precipitation than those that were usually cloudy.

As yet no algorithm has been developed to compute $E T$ from SIF, but we plot tower ET together with SIF in both 2015 and 2016 (Figure 9 a, b) to compare their seasonal 
patterns. Tower ET and SIF had similar seasonal patterns, and tower ET had reasonable correlations ( $\left.r_{2}\right) 0.69$ and 0.73 with SIF in 2015 and 2016, respectively (Figure S13). Comparison of MODIS ET and the tower observations (Table S5) shows that on average MODIS ET is less than the tower ET by approximately $23 \%$ with low to $17 \%$ and up to $29 \%$ during the observation periods in 2015 and 2016 , respectively.

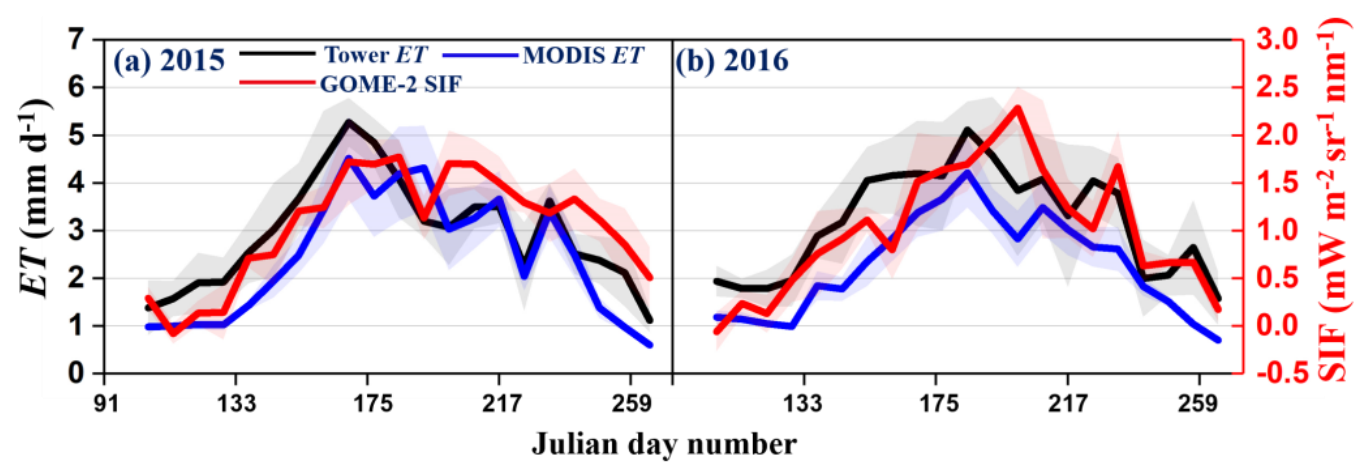

Figure 9. Panel (a)-(b): Evaluation of correlation between MODIS ET or GOME-2 SIF (mean \pm s.e.) and ET observed at the Mohe site. MODIS ET and GOME-2 SIF were both retrieved for $40 \mathrm{~km}$ blocks centered on the Mohe tower.

\section{Discussion}

\subsection{Flux gap filling and nighttime transpiration in boreal larch forest}

Although it is necessary for calculating flux integrals over intervals longer than individual half hours, gap filling of flux data remains challenging and introduces large uncertainty. Some frequent-used conventional methodologies (e.g., mean diurnal variations and lookup tables, etc.), account for flux dependence on a limited number of factors and capture the mean value (Falge et al., 2001). However, ecosystems are complex systems that comprise multiple biotic and abiotic components that may interact with each other through both linear and non-linear ways (Levin, 1998). In recent decades, machine learning has become the focus of much attention, and is a state-of-the-art solution for extracting patterns and insights from earth system data (Reichstein et al., 2019), due to the wide range of its applicability and the ease with which it can handle both linear and non-linear sectors of the data simultaneously (Lek and Guégan, 1999; Olden et al., 2008).

We show here preliminary applications of machine learning in the gap-filling of water fluxes for boreal forests. The machine learning approach is chosen because it does not impose any functional forms (Lek and Guégan, 1999; Olden et al., 2008). Trained by a set of fundamental micrometeorological variables, the RandomForest algorithm yields overall accurate predictions of ET in boreal larch forest. However, we emphasize that its application to other ecosystems still needs to be further verified and spatial and temporal scales of input data are an important factor limiting the performance of machine learning algorithms (Whitley et al., 2009; Mehdizadeh, 2018).

Furthermore, this is the first study that determines the nighttime xylem refilling in boreal larch forest ( $80 \%-95 \%$ depending on tree classes). Nighttime xylem refilling is a critical plant functional trait that enables them to transpire faster than water can be 
transported from the roots for short periods during the day. During the early morning, sap-flow that initiates in the upper trunk utilizes stored water, and the onset of sapflows at the base of the trunk is usually delayed by minutes to hours (Scholz et al., 2008). Using stored water allows plants to keep stomata open and continue to photosynthesize longer. Also, releasing stored water buffers the negative water potential in xylem, while without buffering, the high tension could result in cavitation, which causes unrepairable damage to the water transport system. Hydraulic resistance in the stem can limit water transport from roots to foliage (Whitehead, 1998). The situation where evaporation demand exceeds water uptake will lead to a hysteresis response between soil water supply and stoma water losses (Buckley, 2005). The depleted water stores are thus to be refilled during the night.

\subsection{Microclimates in China's boreal larch forest}

Microclimatic conditions are significant factors affecting structure and function of forest ecosystems (Arx et al., 2013), whereas feedbacks of the forest ecosystem to climate systems will modify precipitation regimes (Lotsch et al., 2003). Patterns of precipitation, length of various phenophase and their interactions limit levels of transpiration and ET of larch. We saw air temperature, net radiation, and vapor pressure deficit are the main external variables that control water exchange processes in boreal larch forest (also consistent with Law et al., 2002; Motzer et al., 2005; Mackay et al., 2007). The microclimatic regulations on ET during precipitation extremes are more complicated than normal situations because $E T$ is the sum of transpiration and evaporation that are independently influenced by microclimate with varied relative contributions (Katul et al., 2012). Our results suggest precipitation excess will alter ecosystem energy limits and change evaporation and transpiration partitioning in boreal larch ecosystem (Zeppel et al., 2008).

Transpiration itself will be reduced in situations of precipitation excess (Wullschleger and Hanson, 2006). Evaporation of boreal larch will be increased at the same time because it was calculated as the residuals between ET and T. Meanwhile, wet surface is often associated with the periods of excess precipitation, so there is adequate water to be evaporated. In this study, precipitation came in the form of frequent cloudy days with small amounts of precipitation for each event (Figure S5). But receiving excess precipitation by way of infrequent but larger events might have a different effect on the ecosystem. Also, data showed evaporation is controlled primarily by the soil-air vapor pressure gradient (Wehr et al., 2017), but not direct effects from radiations, temperatures, and humidity. Altogether, ET comes close to the ideal PET value and does not go up particularly for the excess precipitation year. This represented that the ecosystem water transportation is likely energy limited but not moisture limited. However, observation during a year with below regional precipitation is needed to test some assumptions related to precipitation deficiency.

High latitude ecosystems are prone to ecological degradation due to the recent frequent and intensified climate anomalies (Melillo et al., 2002; Schuur et al., 2015). At Mohe site, we observe temperature-precipitation anomalies are more frequent in the most recent decade. Arctic-amplification, the more rapid warming of high northern latitudes compared to the global average (Cohen et al., 2014), could be a controlling 
factor. Also, the long-term local temperature-precipitation record illustrates a tight correlation between temperature and precipitation patterns, especially during larch's growing season. The coupling between precipitation and temperature introduces complexity in ecosystem response to climate change (Nolan et al., 2018).

\subsection{Transpiration and evapotranspiration in response to the exterior and interior forcing}

Vegetation phenology, as the long-term adaption and acclimation strategy to local climate, is another factor affecting larch's water fluxes. Patterns and partitioning of water flux components in larch's leaf full-expansion phenophase can determine the intra-annual water budgets due to a larger amount of exchanged water. While in nongrowing season or the earlier growing season, trees have low transpiration capacity because they have no leaves, or their stomatal are not yet functional. The precipitation baselines and phenology patterns in 2015 and 2016 represent contrasting conditions within the range of interannual variability. Transition from dormancy to spring onset in 2016 has higher air temperature and soil water content than in 2015, which provide insights on how the boreal larch forest would respond in a warmer and wetter climate that has an earlier spring onset and extended growing season length (GSL; Menzel and Fabian, 1999; Chen et al., 2005).

There is a recent trend of increasing GSL in northern ecosystems (White et al., 1999). Small changes in the timing of spring growth will strongly control the annual carbon exchange (Goulden et al., 1996), and due to coupling of carbon and water fluxes in terrestrial ecosystems, annual water budgets should respond similarly. For instance, we show the extended GSL in 2016 is possibly the result of excess moisture (i.e., precipitation anomaly), where 1 day increase in GSL will change larch's ET by $1.2 \%$ (2015)-1.4\% (2016). This variation is considerably larger than the $0.2 \%$ alteration for eastern US deciduous broadleaf forest reported by White et al., 1999.

In addition, intraspecies competition (to light) influences ET partitioning. Overall, transpiration, as the most robust engine for water transportation in boreal larch forest, is consistent with other ecosystems worldwide (Jasechko et al., 2013; Schlesinger and Jasechko, 2014). When separating the total transpiration flux into three larch classes, we find dominant trees are the major transpiration source in the ecosystem $E T$, while intermediate and suppressed trees account for the reminder with comparable levels. Transpiration from leaf-full-expansion phenophase is governing the ET partitioning, while excess precipitation increases the proportion of evaporation in the total ET.

Precipitation utilization by ecosystems, also recognized as ecosystem hydraulic strategy, is a complex function influencing the ecosystem functional traits (West et al., 2008). In this study, we define Ecosystem Water Availability (EWA) as the difference between precipitation and ET (EWAd for site-level evaluations in Figure 7) or as ratio of ET to precipitation (EWAr for uniform global comparisons). EWA contributes to groundwater recharge and streamflow. Excess precipitation could maintain the saturation in permafrost active layer, which affects whether the organic soils are oxic or anoxic. EWA also affects active layer depth because water conducts heat more effectively than air-filled pore spaces. 
In boreal ecosystems which are accustomed to using all the water it gets through the year would be strongly affected if permafrost melted and water could drain away quickly. The water that pools in spring and additional water that becomes available over summer as thaw progresses down to base of active layer would no longer be available to support ET in late summer. At Mohe site, we observe ET slightly exceeds precipitation in 2015 (-81 $\mathrm{mm}$ water deficit), whereas precipitation greatly exceeds ET in 2016 ( $+215 \mathrm{~mm}$ water surplus). EWA also linked closely to terrestrial carbon sequestrations. Boreal soils tend to be rich in organic matter (boreal evergreen vs. Mohe: 92.6 vs. 107.6 Mg ha-1; Data by GSOCmap on http://54.229.242.119/GSOCmap/ and by field experiments at Mohe) that decomposes slowly on account of anoxic conditions when it is saturated together with freezing conditions. Moreover, anoxia promotes methanogenesis while oxic conditions allow methanotroph (Oswald et al., 2016). When soil drying allows aeration, decomposition rates increase (Deluca and Boisvenue, 2012). For example, carbon accumulation in the soil will be the greatest under water-saturated conditions (positive water deficit). Soil drying (water deficit) and rewetting (water surplus) cycles enhance substrate decomposition similar to freeze-thaw effects (Fierer et al., 2002).

\subsection{Estimation of water in boreal larch zones from remote-sensing data}

MODIS ET has been well evaluated and optimized by site-level measurements in most vegetation ecosystems, with the notable exception of boreal larch forest ( $\mathrm{Mu}$ et al., 2007; Mu et al., 2011). The empirical ecosystem parameters based on evergreen conifers that were applied to the boreal deciduous forests in Siberia would be questionable (Reich et al., 1998). Previous studies using FLUXNET data showed that MODIS ET generally correlated well with the observed ET in the conterminous US but had residuals of $25 \%-50 \%$ (Velpuri et al., 2013). The relative error of MODIS ET in a Finnish boreal forest was nearly 35\% (Sánchez et al., 2007). We estimated, in boreal larch forest, relative underestimation was approximately $17 \%$ for normal precipitation situations but increased up to $29 \%$ for a year with excess precipitation.

Uncertainties in MODIS products can be attributed to the reduction in valid observations and biased calculation algorithms. We find negative correlation between MODIS quality and precipitation frequency, which suggests some errors might remain after removing cloud-contaminated pixels and cloud screening is not completely effective (Walther et al., 2016). The theoretical basis for the MODIS ET calculation comes from the Penman-Monteith equation (Mu et al., 2007). P-M equation is a commonly used hydrological model and predicts the rate of surface water fluxes by following a single-layer 'big-leaf' approach (Estevez et al., 2009). It is a good tool in some well-studied ecosystems with verified input parameters (Bond-Lamberty et al., 2011; Tian et al., 2011; Sun et al., 2014; Sun et al., 2016). However, it may be biased for data-poor ecosystems, for instance, the boreal larch forest.

Furthermore, spatial heterogeneity in the boreal larch landscape adds to uncertainty when comparing MODIS ET to site-level ET. To mediate these uncertainties in boreal larch forest, we adjust the MODIS ET magnitudes by errors we determined, and we select the 40-km resolution pixels to reflect the regional ET situations for global comparisons across different ecosystems. Our results also show that GOME-2 SIF is a 
more reliable indicator that correlates tightly with ecosystem water fluxes in boreal larch zones than MODIS ET. The close correlation between SIF and ET is consistent with the previous study by Lu et al. (2018). This finding again reveals a great potential of SIF in investigating the regional water dynamics and budgets.

\subsection{Water exchanges by boreal larch forest: a global perspective}

The ratio, T/ET, indicates the extent of vegetation dominance in an ecosystem. We find growing season $T / E T$ in boreal larch at Mohe was approximately $75 \%(\mathrm{CI} 95 \%=$ $18 \%$ ) with a high of $84 \%$ in the normal precipitation year and a low of $66 \%$ in the excess precipitation year. T/ET of boreal larch is comparable to the global average ( $\sim 65 \%$ ) for boreal forest reported by Schlesinger and Jasechko (2014). North American boreal spruce forests had a higher $T / E T$ ratio from $70-80 \%$, and European boreal evergreen forests had lower $T / E T$ of $\sim 50 \%$. Accounting for boreal larch forest based on the Mohe results would not shift the overall boreal forest average significantly. Schlesinger and Jasechko's (2014) overall conclusion that tropical rainforests and temperate forests have higher $T / E T$ than boreal forests remains valid (Figure S1).

We applied the EWAr (Section 4.3) to understand vegetation roles in maintaining ecosystem water budgets through 23 global boreal-temperate-tropical forest sites from 2000 to 2018 (Figure 10a). In order to allow for different timing of growing seasons between biomes and duration of wet and dry or warm and cold seasons we compared EWAr on annual time increments (Figure S14). Although the range of EWAr has overlap across the ecosystem types, the general trend is for boreal $>$ temperate $>$ tropical (Figure 10b). EWAr is negatively correlated with latitude in boreal and tropical zones but not the temperate zone (Figure 10c). Although tropical rainforest has the highest average ET, it has the lowest EWAr. The low values indicate water supply from precipitation exceeds ecosystem requirements. ET in boreal forests tends to consume a large fraction of available water input putting them at a closer risk for periods of moisture limitation (Table S7). Also, EWAr in RU-SkP and US-Prr are larger than 1.0 (Figure 10b). Persistent ecological disturbances, including waterlogging and wildfires, are possibly major reasons that affect ecosystem water availability in these two sites (Iwata, et al., 2011; Ohta et al., 2014).

The comparison of EWAr points out variation in water across the boreal biome. The two deciduous conifer sites, RU-SkP and CN-Moh, have comparable ET (365 \pm 84 . $\mathrm{mm})$ to the other 7 evergreen conifers $(389 \pm 70 \mathrm{~mm})$. However, EWAr in deciduous $(1.1 \pm 0.1)$ is distinctly larger than in evergreens $(0.8 \pm 0.3)$. The deciduous habit of boreal larch may be an adaptation to generally dryer and cooler climate that evergreen boreal conifers experience. We emphasize that vegetation roles in regional water budgets across the entire boreal zone remains uncertain on account of sparse data coverage throughout large portions of the boreal zone and in particular limited information on the differences in water exchange properties between deciduous and evergreen conifers. 
(a) $2000-2018$

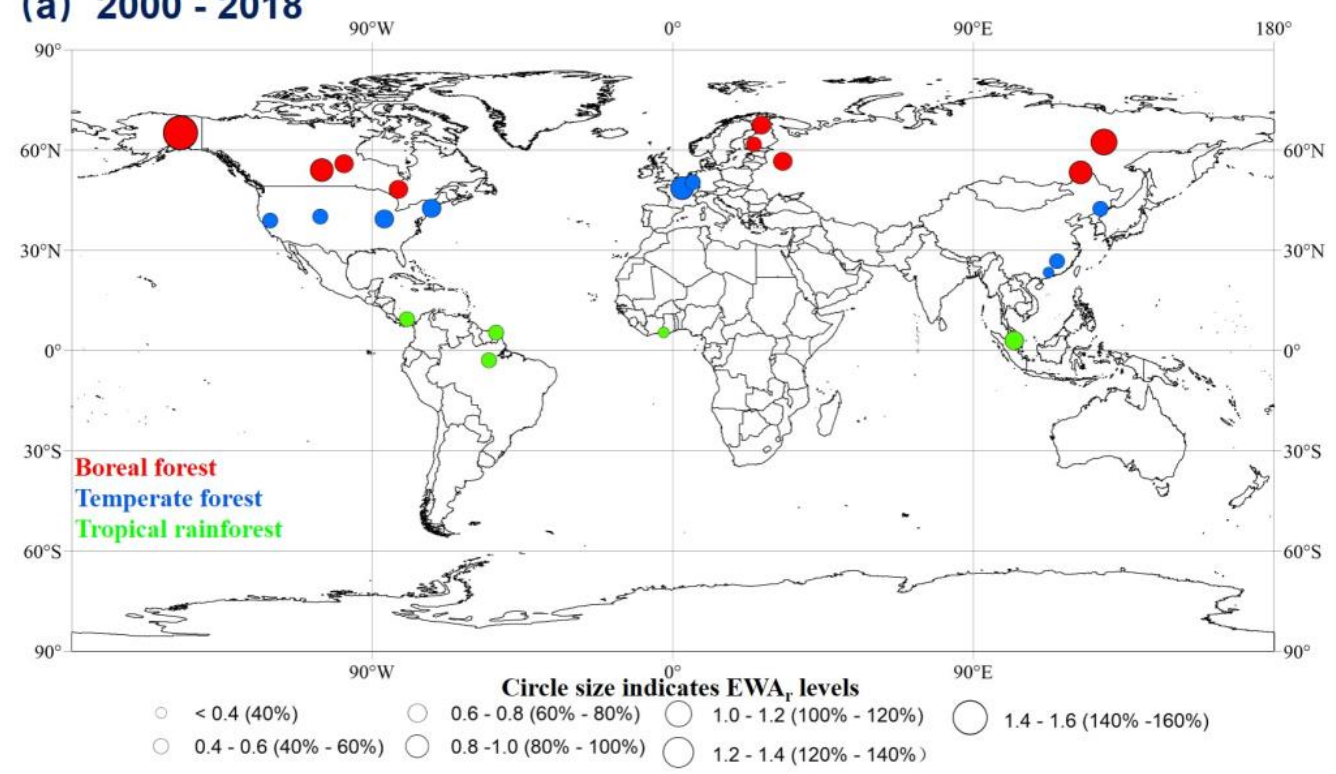

873

874

875

876

877

878

879

880

881

882

883

884

885

886

887

888

889

890
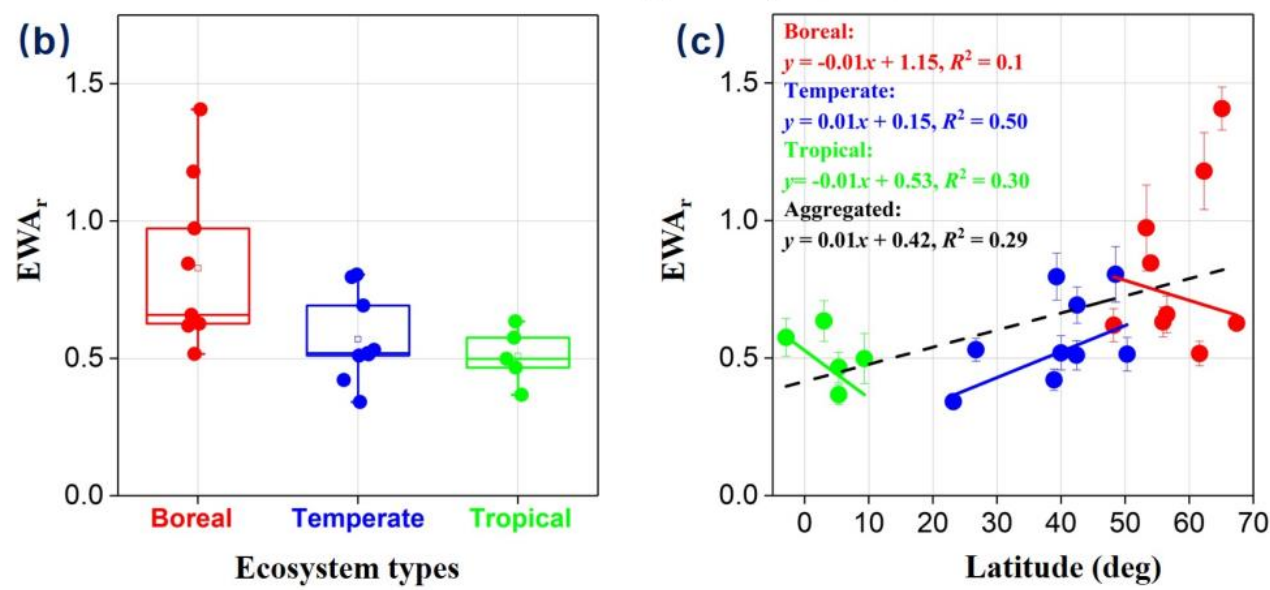

Figure 10. Panel (a): Overviews of EWAr (ecosystem water availability; here calculated as the ratio of $E T$ to precipitation) derived from 23 boreal-temperatetropical forest sites in periods of 2000-2018. Specifically, MODIS ET is derived from 2000-2018, whereas precipitation is the mean annual precipitation recorded by FLUXNET. Panel (b): Comparisons of EWAr (19 year averaged) between sampled sites. Panel (c): Regressions between EWAr (error bars indicated \pm s.d.) and latitudes for sampled sites. Larger EWAr represents ecosystem consumes more of available water. MODIS ET in two boreal larch sites (CN-Moh and RU-SkP) was increased by $23 \%$ (discussed in sections 3.6 and 4.4 ). The $23 \%$ adjustment will increase EWAr values in two sites but not affect the overall ranks across different biomes. Supplementary data given in Table S7.

\section{Conclusions}

At the Mohe site, long-term precipitation patterns are positively correlated with the regional temperature patterns, which reveals a complex temperature-precipitation interaction. Predicting vegetation response to climate change will require consideration of the interactions and not simply response to temperature or moisture acting alone. The interaction between precipitation and phenology influences not only 
the seasonal and inter-annual patterns of evapotranspiration but also its partitioning between transpiration and evaporation.

Short-term precipitation extremes may shift ecosystem function and structure by changing the distribution between water available to the ecosystem and exported as runoff. Evapotranspiration slightly exceeds precipitation from April to October in 2015 and precipitation exceeds evapotranspiration by a factor of 1.4 during the same period in 2016. Ecosystem water availability will further influence groundwater recharge, streamflow, and heat transfer to the permafrost. When excess water keeps soils in the active layer saturated, anoxic conditions that suppress decomposition rates prevail and contribute to accumulation of organic carbon soils. Water deficits that allowed enhanced soil aeration could accelerate decomposition.

Nighttime xylem refilling accounts for $80 \%-95 \%$ of nighttime transpiration, which is $2 \%-9 \%$ of the daily total transpiration. Inadequate separation of xylem refilling and actual water loss overestimates the vegetation water budgets, particularly during the warmer but shorter growing seasons in the boreal zone. Transpiration is the dominant water flux (66-84\%) in boreal larch forest. From dormant to the early growing seasons, transpiration constitutes the majority of evapotranspiration due to the negative soil-air vapor pressure gradient; soil surface and standing water remain colder than the dewpoints in the air. In the peak growing season when the canopy is fully expanded, excess precipitation reduces transpiration, but enhances evaporation. The combination of higher humidity and cooler foliage reduces vapor pressure deficit, and less water is lost for a given stomatal opening. At the same time, precipitation leaves more intercepted water on the canopy and trunk that can evaporate.

The ratio of transpiration to evapotranspiration in boreal larch forest is within range observed at other boreal sites and is smaller than the ratios observed for temperate and tropical forests. Tropical forests exchange more evapotranspiration but because they have even higher precipitation inputs the fraction of water consumed by the ecosystem as evapotranspiration is smaller. On the other hand, boreal forests have less evapotranspiration but they tend to consume a larger fraction of their precipitation input. This finding is critical for understanding global patterns of forest productivity and points to different adaptations to water supply where ecosystems accustomed to an abundant supply of precipitation are not able to cope as well to dry anomalies. Notably, boreal deciduous larch is a unique boreal functional type that differs from evergreens due to distinct hydrological properties, including a heavier consumption of precipitation and a better adaption to the dryer and cooler climates. Comparison of ecosystem-scale hydrologic properties across biomes shows vegetation adaptation for the current climate conditions. Differences in ecosystem hydrologic properties may impact their ability to adapt to short and long-term climate anomalies. 
Abaimov, A. P., 2010. Geographical distribution and genetics of Siberian larch species. Permafrost Ecosystems, Springer, Netherlands, 41-58.

Adler, R. F., Huffman, G. J., Chang, A., Ferraro, R., Xie, P. P., Janowiak, J., Rudolf, B., Schneider, U., Curtis, S., Bolvin, D., and Gruber, A., 2003. The Version 2 Global Precipitation Climatology Project (GPCP) monthly precipitation analysis (1979-present). Journal of Hydrometeorology, 4(6): 1147-1167.

Amiro, B., 2009. Measuring boreal forest evapotranspiration using the energy balance residual. Journal of Hydrology, 366(1-4): 112-118.

Arx, G., Graf Pannatier, E., Thimonier, A., and Rebetez, M., 2013. Microclimate in forests with varying leaf area index and soil moisture: potential implications for seedling establishment in a changing climate. Journal of Ecology, 101(5): 1201-1213.

Austin, A. T., Yahdjian, L., Stark, J. M., Belnap, J., Porporato, A., Norton, U., Ravetta, D. A., and Schaeffer, S. M., 2004. Water pulses and biogeochemical cycles in arid and semiarid ecosystems. Oecologia, 141(2): 221-235.

Bond-Lamberty, B., Gower, S. T., Amiro, B., and Ewers, B. E., 2011. Measurement and modeling of bryophyte evaporation in a boreal forest chronosequence. Ecohydrology, 4 (1): 26-35.

Borchert, R., 1994. Soil and stem water storage determine phenology and distribution of tropical dry forest trees. Ecology, 75(5): 1437-1449.

Borchert, R. and Pockman, W. T., 2005. Water storage capacitance and xylem tension in isolated branches of temperate and tropical trees. Tree Physiology, 25(4): 457-466.

Breiman, L., 2001. Random forests. Machine Learning, 45(1): 5-32.

Buckley, T. N., 2005. The control of stomata by water balance. New Phytologist, 168(2): 275-292.

Cavanaugh, M. L., Kurc, S. A., and Scott, R. L., 2011. Evapotranspiration partitioning in semiarid shrubland ecosystems: a two-site evaluation of soil moisture control on transpiration. Ecohydrology, 4(5): 671-681.

Chen, X., Hu, B., and Yu, R., 2005. Spatial and temporal variation of phenological growing season and climate change impacts in temperate eastern China. Global Change Biology, 11(7): 1118-1130.

Coenders-Gerrits, A. M. J., Van der Ent, R. J., Bogaard, T. A., Wang-Erlandsson, L., Hrachowitz, M., and Savenije, H. H. G., 2014. Uncertainties in transpiration estimates. Nature, 506(7487): E1-E2.

Cohen, J., Screen, J. A., Furtado, J. C., Barlow, M., Whittleston, D., Coumou, D., Francis, J., Dethloff, K., Entekhabi, D., Overland, J., and Jones, J., 2014. Recent Arctic amplification and extreme mid- 
Cutler, D. R., Edwards Jr, T. C., Beard, K. H., Cutler, A., Hess, K. T., Gibson, J., and Lawler, J. J., 2007. Random forests for classification in ecology. Ecology, 88(11): 2783-2792.

Deguchi, A., Hattori, S., Daikoku, K., and Park, H. T., 2008. Measurement of evaporation from the forest floor in a deciduous forest throughout the year using microlysimeter and closed-chamber systems. Hydrological Processes, 22(18): 3712-3723.

Deluca, T. H. and Boisvenue, C., 2012. Boreal forest soil carbon: distribution, function and modelling. Forestry, 85(2): 161-184.

Diffenbaugh, N. S., Swain, D. L., and Touma, D., 2015. Anthropogenic warming has increased drought risk in California. Proceedings of the National Academy of Sciences, 112(13): 3931-3936.

Dutta, K., Schuur, E., Neff, J., and Zimov, S., 2006. Potential carbon release from permafrost soils of Northeastern Siberia. Global Change Biology, 12(12): 2336-2351.

Endo, H., Kitoh, A., Mizuta, R., and Ishii, M., 2017. Future changes in precipitation extremes in East Asia and their uncertainty based on large ensemble simulations with a high-resolution AGCM. SOLA, 13: 7-12.

Esper, J. and Schweingruber, F. H., 2004. Large-scale treeline changes recorded in Siberia. Geophysical Research Letters, 31.

Estevez, J., Gavilan, P., and Berengena, J., 2009. Sensitivity analysis of a Penman-Monteith type equation to estimate reference evapotranspiration in southern Spain. Hydrological Processes, 23(23): 3342-3353.

Evans, P. and Brown, C. D., 2017. The boreal-temperate forest ecotone response to climate change. Environmental Reviews, 25(4): 423-431.

Falge, E., Baldocchi, D., Olson, R., Anthoni, P., Aubinet, M., Bernhofer, C., Burba, G., Ceulemans, R., Clement, R., Dolman, H., and Granier, A., 2001. Gap filling strategies for defensible annual sums of net ecosystem exchange. Agricultural and Forest Meteorology, 107(1): 43-69.

Fierer, N., Schimel, J. P., and Holden, P. A., 2003. Influence of drying-rewetting frequency on soil bacterial community structure. Microbial Ecology, 45(1): 63-71.

Fisher, J. B., Baldocchi, D. D., Misson, L., Dawson, T. E., and Goldstein, A. H., 2007. What the towers don't see at night: nocturnal sap flow in trees and shrubs at two AmeriFlux sites in California. Tree Physiology, 27(4): 597-610.

Frankenberg, C., O’Dell, C., Guanter, L., and McDuffie, J., 2012. Remote sensing of near-infrared chlorophyll fluorescence from space in scattering atmospheres: implications for its retrieval and interferences with atmospheric $\mathrm{CO}_{2}$ retrievals. Atmospheric Measurement Techniques, 5(8): 2081- 
Fyllas, N. M., Bentley, L. P., Shenkin, A., Asner, G. P., Atkin, O. K., Díaz, S., Enquist, B. J., FarfanRios, W., Gloor, E., Guerrieri, R., and Huasco, W. H., 2017. Solar radiation and functional traits explain the decline of forest primary productivity along a tropical elevation gradient. Ecology Letters, 20(6): 730-740.

Granier, A., 1985. A new method of sap flow measurement in tree stems. Annales des Sciences Forestières, 42: 193-200.

Good, S. P., David, N., and Gabriel, B., 2015. Hydrologic connectivity constrains partitioning of global terrestrial water fluxes. Science, 349(6244): 175-177.

Goulden, M. L., Munger, J. W., Fan, S. M., Daube, B. C., and Wofsy, S. C., 1996. Measurements of carbon sequestration by long-term eddy covariance: Methods and a critical evaluation of accuracy. Global Change Biology, 2(3): 169-182.

Gu, L., Falge, E. M., Boden, T., Baldocchi, D. D., and Black, T. A., 2005. Objective threshold determination for nighttime eddy flux filtering. Agricultural and Forest Meteorology, 128(3-4): 179-197.

Guan, K., Pan, M., Li, H., Wolf, A., Wu, J., Medvigy, D., Caylor, K. K., Sheffield, J., Wood, E. F., Malhi, Y., and Liang, M., 2015. Photosynthetic seasonality of global tropical forests constrained by hydroclimate. Nature Geoscience, 8(4): 284.

Guo, W., Liu, H., Anenkhonov, O. A., Shangguan, H., Sandanov, D. V., Korolyuk, A. Y., Hu, G., and $\mathrm{Wu}, \mathrm{X} ., 2018$. Vegetation can strongly regulate permafrost degradation at its southern edge through changing surface freeze-thaw processes. Agricultural and Forest Meteorology, 252: 1017.

Hall, D. K., and Riggs, G. A., 2016. MODIS/Terra Snow Cover 8-Day L3 Global 500m Grid, Version 6. Boulder, Colorado USA. NASA National Snow and Ice Data Center Distributed Active Archive Center. https://doi.org/10.5067/MODIS/MOD10A2.006.

Iverson, L. R., Prasad, A. M., Matthews, S. N., and Peters, M., 2007. Estimating potential habitat for 134 eastern US tree species under six climate scenarios. Forest Ecology and Management, 254(3): 390-406.

Iwata, H., Ueyama, M., Harazono, Y., Tsuyuzaki, S., Kondo, M., and Uchida, M., 2011. Quick recovery of carbon dioxide exchanges in a burned black spruce forest in interior Alaska. SOLA, 7: 105108.

Jasechko, S., Sharp, Z. D., Gibson, J. J., Birks, S. J., Yi, Y., and Fawcett, P. J., 2013. Terrestrial water fluxes dominated by transpiration. Nature, 496(7445): 347. 
Jin, H., Yu, Q., Lü, L., Guo, D., He, R., Yu, S., Sun, G., and Li, Y., 2007. Degradation of permafrost in the Xing'anling Mountains, Northeastern China. Permafrost and Periglacial Processes, 18(3): 245258.

Joiner, J., Yoshida, Y., Vasilkov, A. P., Schaefer, K., Jung, M., Guanter, L., Zhang, Y., Garrity, S., Middleton, E. M., Huemmrich, K. F., and Gu, L., 2014. The seasonal cycle of satellite chlorophyll fluorescence observations and its relationship to vegetation phenology and ecosystem atmosphere carbon exchange. Remote Sensing of Environment, 152: 375-391.

Katul, G. G., Oren, R., Manzoni, S., Higgins, C., and Parlange, M. B., 2012. Evapotranspiration: a process driving mass transport and energy exchange in the soil-plant-atmosphere-climate system. Reviews of Geophysics, 50(3): RG3002.

Kim, J. H., Hwang, T., Yang, Y., Schaaf, C. L., Boose, E., and Munger, J. W., 2018. Warming-induced earlier greenup leads to reduced stream discharge in a temperate mixed forest catchment. Journal of Geophysical Research: Biogeosciences. 123: 1960-1975.

Kool, D., Agam, N., Lazarovitch, N., Heitman, J. L., Sauer, T. J., and Ben-Gal, A., 2014. A review of approaches for evapotranspiration partitioning. Agricultural and Forest Meteorology, 184: 56-70.

Kool, D., Kustas, W. P., Ben-Gal, A., Lazarovitch, N., Heitman, J. L., Sauer, T. J., and Agam, N., 2016. Energy and evapotranspiration partitioning in a desert vineyard. Agricultural and Forest Meteorology, 218: 277-287.

Labrière, N., Locatelli, B., Vieilledent, G., Kharisma, S., Basuki, I., Gond, V., and Laumonier, Y., 2016. Spatial congruence between carbon and biodiversity across forest landscapes of northern Borneo. Global Ecology and Conservation, 6: 105-120.

Law, B. E., Falge, E., Gu, L. V., Baldocchi, D. D., Bakwin, P., Berbigier, P., Davis, K., Dolman, A. J., Falk, M., Fuentes, J. D., and Goldstein, A., 2002. Environmental controls over carbon dioxide and water vapor exchange of terrestrial vegetation. Agricultural and Forest Meteorology, 113(1): 97120.

Lawrence, D. M., Thornton, P. E., Oleson, K. W., and Bonan, G. B., 2007. The partitioning of evapotranspiration into transpiration, soil evaporation, and canopy evaporation in a GCM: Impacts on land-atmosphere interaction. Journal of Hydrometeorology, 8(4): 862-880.

Lee, J. E., Frankenberg, C., van der Tol, C., Berry, J. A., Guanter, L., Boyce, C. K., Fisher, J. B., Morrow, E., Worden, J. R., Asefi, S., and Badgley, G., 2013. Forest productivity and water stress in Amazonia: Observations from GOSAT chlorophyll fluorescence. Proceedings of the Royal Society of London B: Biological Sciences, 280(1761): 20130171.

Lek, S. and Guégan, J. F., 1999. Artificial neural networks as a tool in ecological modelling, an introduction. Ecological Modelling, 120(2-3): 65-73. 
Levin, S. A., 1998. Ecosystems and the biosphere as complex adaptive systems. Ecosystems, 1(5):431436.

Liu, X. and Zhang, D., 2013. Trend analysis of reference evapotranspiration in Northwest China: the roles of changing wind speed and surface air temperature. Hydrological Processes, 27(26): 39413948 .

Lotsch, A., Friedl, M. A., Anderson, B. T., and Tucker, C. J., 2003. Coupled vegetation-precipitation variability observed from satellite and climate records. Geophysical Research Letters, 30(14): 1774 .

Lu, X., Liu, Z., An, S., Miralles, D. G., Maes, W., Liu, Y., and Tang, J., 2018. Potential of solar-induced chlorophyll fluorescence to estimate transpiration in a temperate forest. Agricultural and Forest Meteorology, 252: 75-87.

Luus, K. A., Commane, R., Parazoo, N. C., Benmergui, J., Euskirchen, E. S., Frankenberg, C., Joiner, J., Lindaas, J., Miller, C. E., Oechel, W. C., and Zona, D., 2017. Tundra photosynthesis captured by satellite-observed solar-induced chlorophyll fluorescence. Geophysical Research Letters, 44(3): $1564-1573$.

Mackay, D. S., Ewers, B. E., Cook, B. D., and Davis, K. J., 2007. Environmental drivers of evapotranspiration in a shrub wetland and an upland forest in northern Wisconsin. Water Resources Research, 43(3): W03442.

Mauder, M., Cuntz, M., Drüe, C., Graf, A., Rebmann, C., Schmid, H. P., Schmidt, M., and Steinbrecher, R., 2013. A strategy for quality and uncertainty assessment of long-term eddy-covariance measurements. Agricultural and Forest Meteorology, 169: 122-135.

Mauder, M., Oncley, S. P., Vogt, R., Weidinger, T., Ribeiro, L., Bernhofer, C., Foken, T., Kohsiek, W., De Bruin, H. A., and Liu, H., 2007. The energy balance experiment EBEX-2000. Part II: Intercomparison of eddy-covariance sensors and post-field data processing methods. BoundaryLayer Meteorology, 123(1): 29-54.

Mehdizadeh, S., 2018. Estimation of daily reference evapotranspiration (ETo) using artificial intelligence methods: offering a new approach for lagged $\mathrm{ET}_{\mathrm{o}}$ data-based modeling. Journal of Hydrology, 559: 794-812.

Melillo, J. M., Steudler, P. A., Aber, J. D., Newkirk, K., Lux, H., Bowles, F. P., Catricala, C., Magill, A., Ahrens, T., and Morrisseau, S., 2002. Soil warming and carbon-cycle feedbacks to the climate system. Science, 298(5601): 2173-2176.

Menzel, A. and Fabian, P., 1999. Growing season extended in Europe. Nature, 397(6721): 659.Mitchell, R., 1992. Testing evolutionary and ecological hypotheses using path analysis and structural equation modelling. Functional Ecology, 6(2): 123-129. https://doi.org/10.1016/S00063207(03)00129-0. 
Motzer, T., Munz, N., Küppers, M., Schmitt, D., and Anhuf, D., 2005. Stomatal conductance, transpiration and sap flow of tropical montane rain forest trees in the southern Ecuadorian Andes. Tree Physiology, 25(10): 1283-1293.

Moran, M. S., Scott, R. L., Keefer, T. O., Emmerich, W. E., Hernandez, M., Nearing, G. S., Paige, G. B., Cosh, M. H., and O’Neill, P. E., 2009. Partitioning evapotranspiration in semiarid grassland and shrubland ecosystems using time series of soil surface temperature. Agricultural and Forest Meteorology, 149(1): 59-72.

Mu, Q., Heinsch, F. A., Zhao, M., and Running, S. W., 2007. Development of a global evapotranspiration algorithm based on MODIS and global meteorology data. Remote Sensing of Environment, 111(4): 519-536.

Mu, Q., Zhao, M., and Running, S. W., 2011. Improvements to a MODIS global terrestrial evapotranspiration algorithm. Remote Sensing of Environment, 115(8): 1781-1800.

Myneni, R., Knyazikhin, Y., and Park, T., 2015. MCD15A3H MODIS/Terra+Aqua Leaf Area Index/FPAR 4-day L4 Global 500m SIN Grid V006. NASA EOSDIS Land Processes DAAC. https://doi.org/10.5067/MODIS/MCD15A3H.006.

Nemani, R. R., Keeling, C. D., Hashimoto, H., Jolly, W. M., Piper, S. C., Tucker, C. J., Myneni, R. B., and Running, S. W., 2003. Climate-driven increases in global terrestrial net primary production from 1982 to 1999 . Science, 300(5625): 1560-1563.

Nolan, C., Overpeck, J. T., Allen, J. R., Anderson, P. M., Betancourt, J. L., Binney, H. A., Brewer, S., Bush, M. B., Chase, B. M., Cheddadi, R., and Djamali, M., 2018. Past and future global transformation of terrestrial ecosystems under climate change. Science, 361(6405): 920-923.

O'Dell, C. W., Connor, B., Bösch, H., O'Brien, D., Frankenberg, C., Castano, R., Christi, M., Eldering, D., Fisher, B., Gunson, M., McDuffie, J., Miller, C. E., Natraj, V., Oyafuso, F., Polonsky, I., Smyth, M., Taylor, T., Toon, G. C., Wennberg, P. O., and Wunch, D., 2012. The ACOS CO2 retrieval algorithm-Part 1: Description and validation against synthetic observations. Atmospheric Measurement Techniques, 5: 99-121.

Ohta, T., Kotani, A., Iijima, Y., Maximov, T. C., Ito, S., Hanamura, M., Alexander, A. K., and Maximov, A. P., 2014. Effects of waterlogging on water and carbon dioxide fluxes and environmental variables in a Siberian larch forest, 1998-2011. Agricultural and Forest Meteorology, 188: 64-75.

Olden, J. D., Lawler, J. J., and Poff, N. L., 2008. Machine learning methods without tears: a primer for ecologists. The Quarterly Review of Biology, 83(2): 171-193.

Oreskes, N., Shrader-Frechette, K., and Belitz, K., 1994. Verification, validation, and confirmation of numerical models in the earth sciences. Science, 263(5147): 641-646.

Ouyang, W., Liu, B., and Wu, Y., 2016. Satellite-based estimation of watershed groundwater storage 

dynamics in a freeze-thaw area under intensive agricultural development. Journal of Hydrology, 537: 96-105.

Oswald, K., Milucka, J., Brand, A., Hach, P., Littmann, S., Wehrli, B., and Kuypers M. M. M., Schubert, C. J., 2016. Aerobic gammaproteobacterial methanotrophs mitigate methane emissions from oxic and anoxic lake waters. Limnology and Oceanography, 61(S1): S101-S118.

Pan, Y., Birdsey, R. A., Fang, J., Houghton, R., Kauppi, P. E., Kurz, W. A., Phillips, O. L., Shvidenko, A., Lewis, S. L., Canadell, J. G., and Ciais, P., 2011. A large and persistent carbon sink in the world's forests. Science, 1201609.

Papale, D., Reichstein, M., Aubinet, M., Canfora, E., Bernhofer, C., Kutsch, W., Longdoz, B., Rambal, S., Valentini, R., and Vesala. T., 2006. Towards a standardized processing of Net Ecosystem Exchange measured with eddy covariance technique: algorithms and uncertainty estimation. Biogeosciences, 3: 571-583.

Peng, C., Ma, Z., Lei, X., Zhu, Q., Chen, H., Wang, W., Liu, S., Li, W., Fang, X., and Zhou, X., 2011. A drought-induced pervasive increase in tree mortality across Canada's boreal forests. Nature Climate Change, 1(9): 467.

Ran, Y. H. and Li, X., 2016. Evaluation of the permafrost stability degradation from 1980 to 2010 in China. Sciences in Cold and Arid Regions, 8(5): 0359-0366.

Raz-Yaseef, N., Yakir, D., Schiller, G., and Cohen, S., 2012. Dynamics of evapotranspiration partitioning in a semi-arid forest as affected by temporal rainfall patterns. Agricultural and Forest Meteorology, 157: 77-85.

Reich, P., Walters, M., Tjoelker, M., Vanderklein, D., and Buschena, C., 1998. Photosynthesis and respiration rates depend on leaf and root morphology and nitrogen concentration in nine boreal tree species differing in relative growth rate. Functional Ecology, 12(3): 395-405.

Reichstein, M., Camps-Valls, G., Stevens, B., Jung, M., Denzler, J., and Carvalhais, N., 2019. Deep learning and process understanding for data-driven Earth system science. Nature, 566(7743): 195.

Rohde, R., Muller, R., Jacobsen, R., Perlmutter, S., Rosenfeld, A., Wurtele, J., Curry, J., Wickham, C., and Mosher, S., 2013. Berkeley earth temperature averaging process. Geoinformatics and Geostatistics: An Overview, 1(2). https://10.4172/2327-4581.1000103.

Sánchez, J. M., Caselles, V., Niclós, R., Valor, E., Coll, C., and Laurila, T., 2007. Evaluation of the Bmethod for determining actual evapotranspiration in a boreal forest from MODIS data. International Journal of Remote Sensing, 28(6): 1231-1250.

Scanlon, T. M. and Kustas, W. P., 2010. Partitioning carbon dioxide and water vapor fluxes using correlation analysis. Agricultural and Forest Meteorology, 150(1): 89-99.

Schlaepfer, D. R., Ewers, B. E., Shuman, B. N., Williams, D. G., Frank, J. M., Massman, W. J., and 
Lauenroth, W. K., 2014. Terrestrial water fluxes dominated by transpiration: Comment. Ecosphere, 5(5): 1-9.

Schlesinger, W. H. and Jasechko, S., 2014. Transpiration in the global water cycle. Agricultural and Forest Meteorology, 189(6): 115-117.

Scholz, F. C., Bucci, S. J., Goldstein, G., Meinzer, F. C., Franco, A. C., and Miralles-Wilhelm, F., 2008. Temporal dynamics of stem expansion and contraction in savanna trees: withdrawal and recharge of stored water. Tree Physiology, 28(3): 469-480.

Schuur, E. A. G., McGuire, A. D., Schädel, C., Grosse, G., Harden, J. W., Hayes, D. J., Hugelius, G., Koven, C. D., Kuhry, P., Lawrence, D. M., and Natali, S. M., 2015. Climate change and the permafrost carbon feedback. Nature, 520(7546): 171.

Schwalm, C. R., Anderegg, W. R., Michalak, A. M., Fisher, J. B., Biondi, F., Koch, G., Litvak, M., Ogle, K., Shaw, J. D., Wolf, A., and Huntzinger, D. N., 2017. Global patterns of drought recovery. Nature, 548(7666): 202.

Scott, R. L., 2010. Using watershed water balance to evaluate the accuracy of eddy covariance evaporation measurements for three semiarid ecosystems. Agricultural and Forest Meteorology, 150(2): 219-225.

Shi, T. T., Guan, D. X., Wu, J. B., Wang, A. Z., Jin, C. J., and Han, S. J., 2008. Comparison of methods for estimating evapotranspiration rate of dry forest canopy: Eddy covariance, Bowen ratio energy balance, and Penman-Monteith equation. Journal of Geophysical Research: Atmospheres, 113: D19116.

Shukla, J., Nobre, C., and Sellers, P., 1990. Amazon deforestation and climate change. Science, 247(4948): 1322-1325.

Sun, X., Onda, Y., Kato, H., Otsuki, K., and Gomi, T., 2014. Partitioning of the total evapotranspiration in a Japanese cypress plantation during the growing season. Ecohydrology, 7(3): 1042-1053.

Sun, Y., Fu, R., Dickinson, R., Joiner, J., Frankenberg, C., Gu, L., Xia, Y., and Fernando, N., 2015. Drought onset mechanisms revealed by satellite solar-induced chlorophyll fluorescence: Insights from two contrasting extreme events. Journal of Geophysical Research: Biogeosciences, 120(11): $2427-2440$.

Sun, X., Onda, Y., Otsuki, K., Kato, H., and Gomi, T., 2016. The effect of strip thinning on forest floor evaporation in a Japanese cypress plantation. Agricultural and Forest Meteorology, 216: 48-57.

Tchebakova, N., Parfenova, E., and Soja, A., 2009. The effects of climate, permafrost and fire on vegetation change in Siberia in a changing climate. Environmental Research Letters, 4(4): 045013.

Tian, F. X., Zhao, C. Y., and Feng, Z. D., 2011. Simulating evapotranspiration of Qinghai spruce (Picea crassifolia) forest in the Qilian Mountains, northwestern China. Journal of Arid Environments, 
Trenberth, K. E., 2011. Changes in precipitation with climate change. Climate Research, 47(1-2): 123138.

Van Dijk, A., Moene, A. F., and De Bruin, H. A. R., 2004. The principles of surface flux physics: theory, practice and description of the ECPACK library, Internal Report 2004/1, Meteorology and Air Quality Group, Wageningen University, Wageningen, the Netherlands, p99.

Velpuri, N. M., Senay, G.B., Singh, R. K., Bohms, S., and Verdin, J. P., 2013. A comprehensive evaluation of two MODIS evapotranspiration products over the conterminous United States: Using point and gridded FLUXNET and water balance ET. Remote Sensing of Environment, 139: 35-49.

White, M. A., Running, S. W., and Thornton, P. E., 1999. The impact of growing-season length variability on carbon assimilation and evapotranspiration over 88 years in the eastern US deciduous forest. International Journal of Biometeorology, 42(3): 139-145.

Wang, W., Xu, J., Gao, Y., Bogoev, I., Cui, J., Deng, L., Hu, C., Liu, C., Liu, S., and Shen, J., 2016. Performance evaluation of an integrated open-path eddy covariance system in a cold desert environment. Journal of Atmospheric and Oceanic Technology, 33(11): 2385-99.

Wehr, R., Commane, R., Munger, J. W., McManus, J. B., Nelson, D. D., Zahniser, M. S., Saleska, S.R., and Wofsy, S. C., 2017. Dynamics of canopy stomatal conductance, transpiration, and evaporation in a temperate deciduous forest, validated by carbonyl sulfide uptake. Biogeosciences, 14(2): 389 401 .

Whitehead, D., 1998. Regulation of stomatal conductance and transpiration in forest canopies. Tree Physiology, 18(8-9): 633-644.

Whitley, R., Medlyn, B., Zeppel, M., Macinnis-Ng, C., and Eamus, D., 2009. Comparing the PenmanMonteith equation and a modified Jarvis-Stewart model with an artificial neural network to estimate stand-scale transpiration and canopy conductance. Journal of Hydrology, 373(1-2): 25666.

Wilson, K. B., Hanson, P. J., Mulholland, P. J., Baldocchi, D. D., and Wullschleger, S. D., 2001. A comparison of methods for determining forest evapotranspiration and its components: sap-flow, soil water budget, eddy covariance and catchment water balance. Agricultural and Forest Meteorology, 106(2): 153-168.

Wullschleger, S. D. and Hanson, P. J., 2006. Sensitivity of canopy transpiration to altered precipitation in an upland oak forest: evidence from a long-term field manipulation study. Global Change Biology, 12(1): 97-109.

Yepez, E. A., Williams, D. G., Scott, R. L., and Lin, G., 2003. Partitioning overstory and understory 
evapotranspiration in a semiarid savanna woodland from the isotopic composition of water vapor. Agricultural and Forest Meteorology, 119(1-2): 53-68.

1235

1236

Yi, S., Wang, X., Qin, Y., Xiang, B., and Ding, Y., 2014. Responses of alpine grassland on QinghaiTibetan plateau to climate warming and permafrost degradation: a modeling perspective. Environmental Research Letters, 9(7): 074014.

Yi, Y., Kimball, J. S., Rawlins, M. A., Moghaddam, M., and Euskirchen, E. S., 2015. The role of snow cover affecting boreal-arctic soil freeze-thaw and carbon dynamics. Biogeosciences, 12(19): 5811-5829.

Zeppel, M. J., Macinnis-Ng, C. M., Yunusa, I. A., Whitley, R. J., and Eamus, D., 2008. Long term trends of stand transpiration in a remnant forest during wet and dry years. Journal of Hydrology, 349(1-2): 200-213.

Zhang, X., Friedl, M. A., Schaaf, C. B., Strahler, A. H., Hodges, J. C. F., Gao, F., Reed, B. C., and Huete, A., 2003. Monitoring vegetation phenology using MODIS. Remote Sensing of Environment, 84(2003): 471-475. 